\title{
A Two-Day Case Study: Comparison of Turbulence Data from an Unmanned Aircraft System with a Model Chain for Complex Terrain
}

\author{
Kjell zum Berge ${ }^{1}$ (D) Martin Schoen ${ }^{1} \cdot$ Moritz Mauz $^{1} \cdot$ Andreas Platis $^{1}$. \\ Bram van Kesteren ${ }^{1}$. Daniel Leukauf ${ }^{2}$. Asmae El Bahlouli ${ }^{3}$. Patrick Letzgus ${ }^{4}$. \\ Hermann Knaus ${ }^{3}$. Jens Bange ${ }^{1}$
}

Received: 26 May 2020 / Accepted: 13 February 2021 / Published online: 29 March 2021

(c) The Author(s) 2021

\begin{abstract}
The airborne measurement platform MASC-3 (Multi-Purpose Airborne Sensor Carrier) is used for measurements over a forested escarpment in the Swabian Alps to evaluate the wind field. Data from flight legs between 20 and $200 \mathrm{~m}$ above the ground on two consecutive days with uphill (westerly) flow in September 2018 are analyzed. In the lowest $140 \mathrm{~m}$ above the ground a speed-up is found with increased turbulence and changes in wind direction directly over the escarpment, whereas in the lowest 20 to $50 \mathrm{~m}$ above the ground a deceleration of the flow is measured. Additionally, simulation results from a numerical model chain based on the Weather Research and Forecasting (WRF) model and an OpenFOAM (Open Source Field Operation and Manipulation) model, developed for complex terrain, are compared to the data captured by MASC-3. The models and measurements compare well for the mean wind speed and inclination angle.
\end{abstract}

Keywords Complex terrain · Turbulence measurement · Unmanned aircraft system · Wind energy

Kjell zum Berge

kjell.zumberge@unituebingen.de

1 Center for Applied Geoscience, Eberhard-Karls-Universitaet Tuebingen, Schnarrenbergstr. 94-96, 72076 Tuebingen, Germany

2 Institute of Meteorology and Climate Research Atmospheric Environmental Research (IMK-IFU), Karlsruhe Institute of Technology KIT, Campus Alpin, Kreuzeckbahnstraße 19, 82467 Garmisch-Partenkirchen, Germany

3 Faculty of Building Services-Energy-Environment, Esslingen University of Applied Sciences, Kanalstrasse 33, 73728 Esslingen, Germany

4 Institute of Aerodynamics and Gas Dynamics (IAG) University of Stuttgart, Pfaffenwaldring 21, 70569 Stuttgart, Germany 


\section{Introduction}

In 2019, wind energy production covered $15 \%$ of the electricity demand for all 28 European Union member states (WindEurope 2019). Due to the increasing numbers of wind turbines erected, the wind-energy research focus is shifting from flat terrain and offshore locations towards complex topography. Orographic effects, such as channeling or the acceleration of near-surface flow, can lead to local increases in wind speed (Wagenbrenner et al. 2016) and thus improvement in wind resource (Clifton et al. 2014).

Compared to flat, homogeneous terrain, measurements and characterization of the atmospheric flow in complex terrain are more challenging. The flow is influenced by the heterogeneous orography, leading to higher levels of turbulence in the lower atmospheric boundary layer (ABL), wind shear, and a less predictable behaviour. These features rapidly change the wind field in both space and time (Wildmann et al. 2017). Lidar and sodar, with their comparatively large averaging volumes, have difficulties measuring the highly heterogeneous flow and its fine structure and turbulence over an escarpment. Static point measurements on towers close to the escarpment cannot be representative for the immediate vicinity (Ayotte et al. 2001) due to the heterogeneity and the non-stationarity of the flow. An unmanned aircraft system (UAS) however allows measurements of small-scale turbulence and the flow field over a larger area at multiple heights. This makes a UAS especially useful for measurements in complex terrain, as it captures the phenomena over certain areas of an escarpment or other complex structures.

In order to answer the questions on how to optimize turbines in complex terrain and extend their service life in such areas, the WindForS research cluster (https://www.windfors.de) has launched the WINSENT (Wind Science and Engineering in Complex Terrain) project. The WINSENT project uses a wind-energy test site at the top of a forested escarpment at the rim of the Swabian Alps in south-western Germany. The aim is to get a complete picture on how to operate wind turbines in complex terrain and develop software tools that simulate the turbines, turbulent structures, and the wind field, as well as changes introduced by the wind turbines. The present study analyzes the undisturbed wind field before the installation of wind turbines at and around the test site. It also compares the UAS measurements with data from a numerical-model chain developed by our project partners, consisting of the mesoscale Weather Research and Forecasting (WRF) model and the meso-microscale URANS (Unsteady Reynolds-Averaged Navier-Stokes) model OpenFOAM (Open Source Field Operation and Manipulation; El-Bahlouli et al. 2019, 2020).

High fidelity numerical airflow models, such as large-eddy simulation (LES) models, have been developed and applied for wind energy applications over the years. These models resolve most of the turbulence and require observational data with an equally high resolution for validation. However, since measurements require an extensive amount of material, personnel, funding, and time, there are only few observational datasets with sufficient spatial and temporal resolution of a wind field in complex terrain. One of these unique datasets can be found in Letson et al. (2018). Datasets such as these are of importance given that small-scale obstacles such as trees may have a significant impact. Such a new dataset is needed to reach high accuracy in model results for the future test site and for the analysis on fatigue loads onto the turbine structures, especially the blades. Apart from wind speed, wind direction, and turbulence, the inclination angle plays a major role for the site assessment of new wind turbines. According to the IEC 60400-1 (VDE 2019) it should not exceed values of $\pm 8^{\circ}$.

During the previous projects Lidar Complex (Hofsaess et al. 2018) and KonTest (Wildmann et al. 2017), measurements with UASs and numerical studies were carried out at this 
site (Fig. 1). Measurements and simulations showed an accelerated flow over the escarpment with westerly winds. Due to surface roughness and the orography, the strongest turbulence fluctuations and flow acceleration were observed at the lowest 10 to $80 \mathrm{~m}$ above ground upstream of the escarpment (Knaus et al. 2018; Letzgus et al. 2018).

In this study, similar measurement flights were conducted. With the latest iteration of the MASC (Multi-Purpose Airborne Sensor Carrier) UAS, the MASC-3 (Rautenberg et al. 2019), we were able to fly much closer to the ground compared to previously (Wildmann et al. 2017) and could not gather these important data downstream the escarpment edge. Due to improved autopilot and more accurate sensors the UAS now provides a more stable flight path that enables measurement trajectories as low as $20 \mathrm{~m}$ above ground (Mauz et al. 2019). Thus MASC-3 covers most of the vertical region of the flow field influenced by the forested escarpment.

The long blades of modern wind turbines reach down into this area with stronger turbulence in the lee of the trees. Knaus et al. (2018) showed that not only orographic effects, but also lee effects of trees affect the flow over an escarpment at these heights. The model results show a significant increase of the turbulence kinetic energy (TKE, $k$ ) and a minimum in wind speed below $50 \mathrm{~m}$ above ground in the lee of the trees (Knaus et al. 2018). Thus, this study aims at answering the following questions:

- Is the MASC-3 able to measure small-scale flow phenomena in complex terrain (such as the propagation of turbulence introduced by the forested escarpment close to the ground), locate recirculation zones along the plateau, and detect differences in wind speed over a large area?

- How well do numerical models resolve small-scale phenomena in comparison to the MASC-3 data?

The results give insight into the turbulence and atmospheric flow within the lower atmospheric boundary layer behind the escarpment on two consecutive days in September 2018, with a focus on the lowest $60 \mathrm{~m}$ above the plateau and close to the future wind-turbine locations. These measurements will give valuable new data for model validation and load calculations within altitudes reached by the turbine blades, which have not been measured before with such a high spatial-temporal resolution.

\section{Measurement System and Site}

\subsection{The Test Site}

The test site $\left(48.664^{\circ} \mathrm{N}, 9.836^{\circ} \mathrm{E}\right)$ is situated on top of a forested escarpment in the Swabian Alps close to the town of Geislingen an der Steige in southern Germany. The forested escarpment peaks at $200 \mathrm{~m}$ above the valley with the slope facing west with no other large obstacles in that direction, except a smaller hill about $2 \mathrm{~km}$ away (Fig. 1). This feature and the predominant westerly winds make this area interesting for building the test site.

Figure 1 shows a digital elevation model of the area with a zoomed view of the future test site. Two measurement masts have been erected close to the escarpment and two more will follow at a later point in time. The masts are equipped with wind vanes, cup anemometers, and pressure-temperature-humidity sensors at heights between 3 and $100 \mathrm{~m}$, which cover the whole wind-turbine diameter. A wind turbine will be placed between each pair of masts. At the time of the measurements, only the north-western tower was equipped with a suite of instruments. 


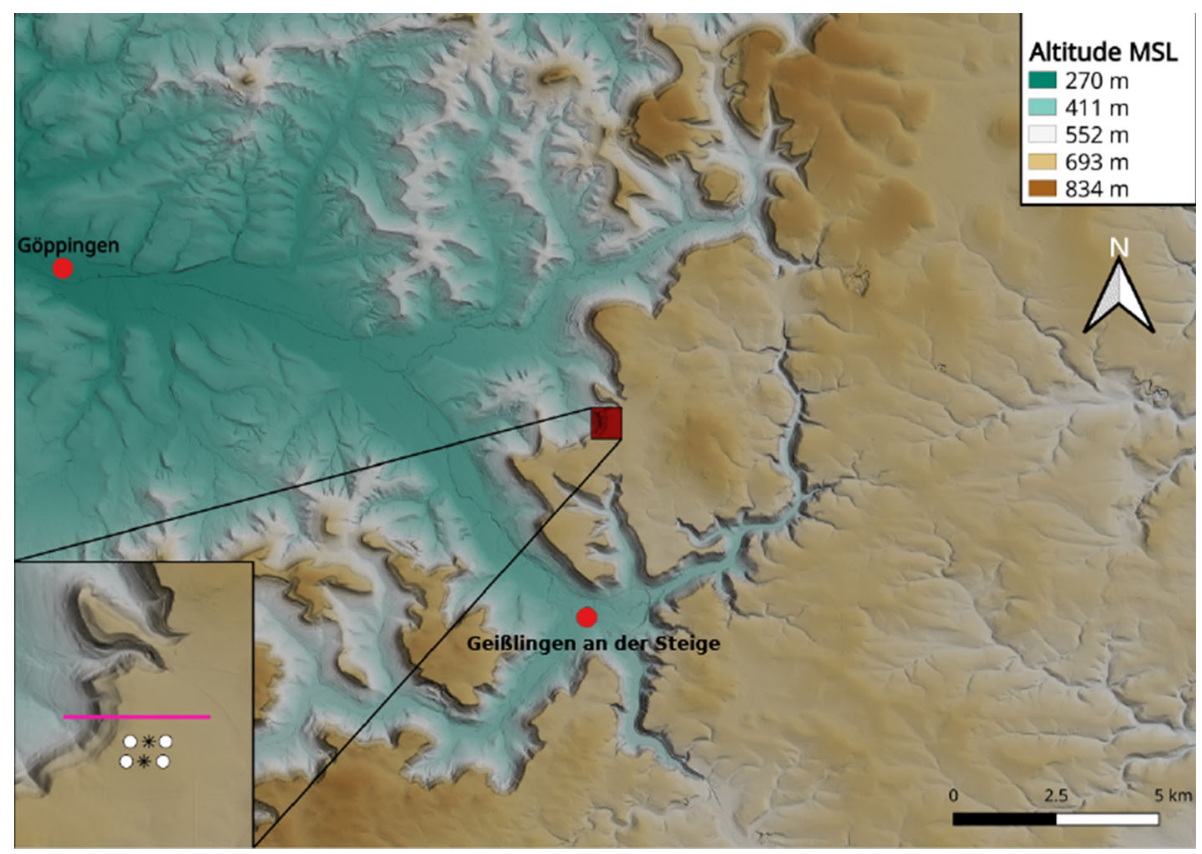

Fig. 1 Digital elevation model of the Albtrauf with the rectangle zooming onto the test site located at $48.664^{\circ} \mathrm{N}$, $9.836^{\circ} \mathrm{E}$. Height difference displayed in the upper right corner. Zoomed View: white dots = wind measurement masts; black stars = future turbines; pink line = flight path; source: DEM5 (Digital Elevation Model $5 \mathrm{~m}$ Resolution) provided by the district office Baden-Württemberg

\subsection{Measurement System}

The latest version of the MASC, the MASC-3 (Rautenberg et al. 2019), is an autonomously flying UAS with a 4-m wingspan and about 6-8 kg mass. This includes 1 to $1.5 \mathrm{~kg}$ of scientific payload (Fig. 2). The flight time can reach up to $2.5 \mathrm{~h}$ depending on payload and battery configuration. The autopilot (Pixhawk 2.1 'Cube') is capable of keeping the position within a few metres with respect to its programmed flight path for most conditions. In this study, the airspeed was fixed to $18.5 \mathrm{~m} \mathrm{~s}^{-1}$ by the autopilot system.

The measuring unit is modular and consists of a sensor suite for measuring the wind vector and air temperature at frequencies up to $30 \mathrm{~s}^{-1}$ (Rautenberg et al. 2019), and water vapour with frequency of about $0.5 \mathrm{~s}^{-1}$. With the pusher engine at the back of the fuselage, the engines influence on measurements at the front of the UAS is minimized.

The five-hole flow probe measures pressure differences between the holes at the front of the aircraft's nose. Together with the motion of the aircraft and current position data from the inertial measurement unit (IMU) in the geodetic coordinate system, the wind vector is calculated from

$$
\mathbf{v}=\mathbf{v}_{\mathrm{gs}}+M\left(\mathbf{v}_{\mathrm{tas}}+\omega \times \mathbf{r}\right)
$$

with the wind vector $\mathbf{v}$ (positive eastwards and upwards), ground speed vector $\mathbf{v}_{\mathrm{gs}}$, airspeed vector $\mathbf{v}_{\text {tas }}$, rotation matrix $M$ to convert from an aerodynamic to a geodetic coordinate system, the vector of angular body rates $\omega$, and the lever arm $\mathbf{r}$ between the IMU and five-hole probe. For a more detailed description of wind measurements with the UAS and error estimations, 


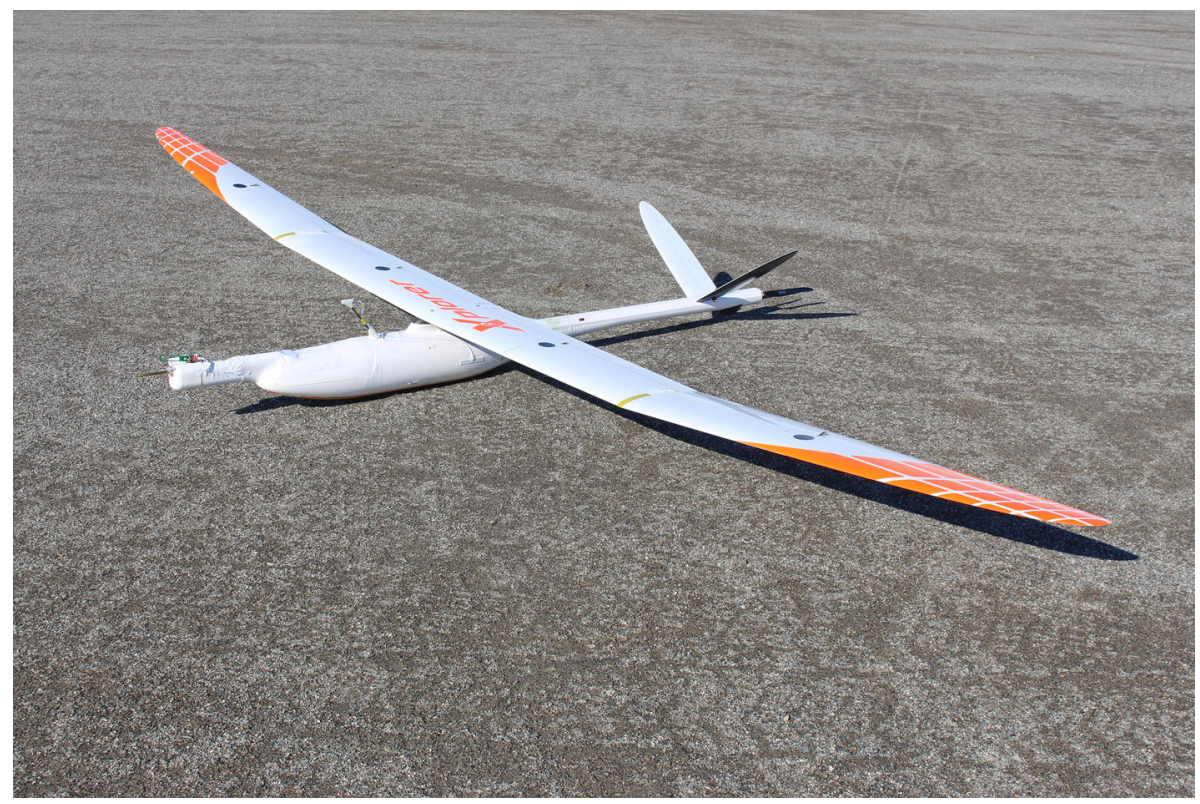

Fig. 2 The Multi-Purpose Airborne Sensor Carrier, version 3 is a UAS for meteorological measurements in the atmospheric boundary layer. The image shows the UAS with its sensor compartment (Rautenberg et al. 2019). Picture taken by Barbara Altstädter

see Van den Kroonenberg et al. (2008), Wildmann et al. (2014, 2017), and Rautenberg et al. (2018).

\section{Methods and Theory}

\subsection{Measurement Strategy}

For the purpose of the flow measurement over the escarpment, flight legs (i.e., straight and level flight paths) at different heights perpendicular to the slope and along the mean wind direction were performed. The lowest flight altitude is $20 \mathrm{~m}$ above ground level (a.g.l.) and therefore just above the tree tops. Up to $60 \mathrm{~m}$ a.g.l., measurements are performed at vertical intervals of $10 \mathrm{~m}$. Above $60 \mathrm{~m}$ the intervals are increased to $20 \mathrm{~m}$ and above $120 \mathrm{~m}$ each height step is $40 \mathrm{~m}$ up to the top height of about $200 \mathrm{~m}$ (Fig. 3). Each level consists of at least four straight flight legs on the same path in opposite directions, giving the data more statistical significance.

With a sampling rate of $500 \mathrm{~s}^{-1}$ for the raw data and $100 \mathrm{~s}^{-1}$ for the processed data, a spatial resolution of 5-6 data points per metre flight path was obtained. The high sampling rate was chosen to counteract the aliasing effect in the output data.

Flight measurements downstream of the edge allow for the analysis of the impact of the escarpment on the flow field. Therefore the flight paths (legs) were chosen to be about $1 \mathrm{~km}$ long with $500 \mathrm{~m}$ in less disturbed flow above the lowland and another $800 \mathrm{~m}$ above the plateau where the future wind turbines will be positioned. Table 1 lists the flights and the metadata for the data used herein. 


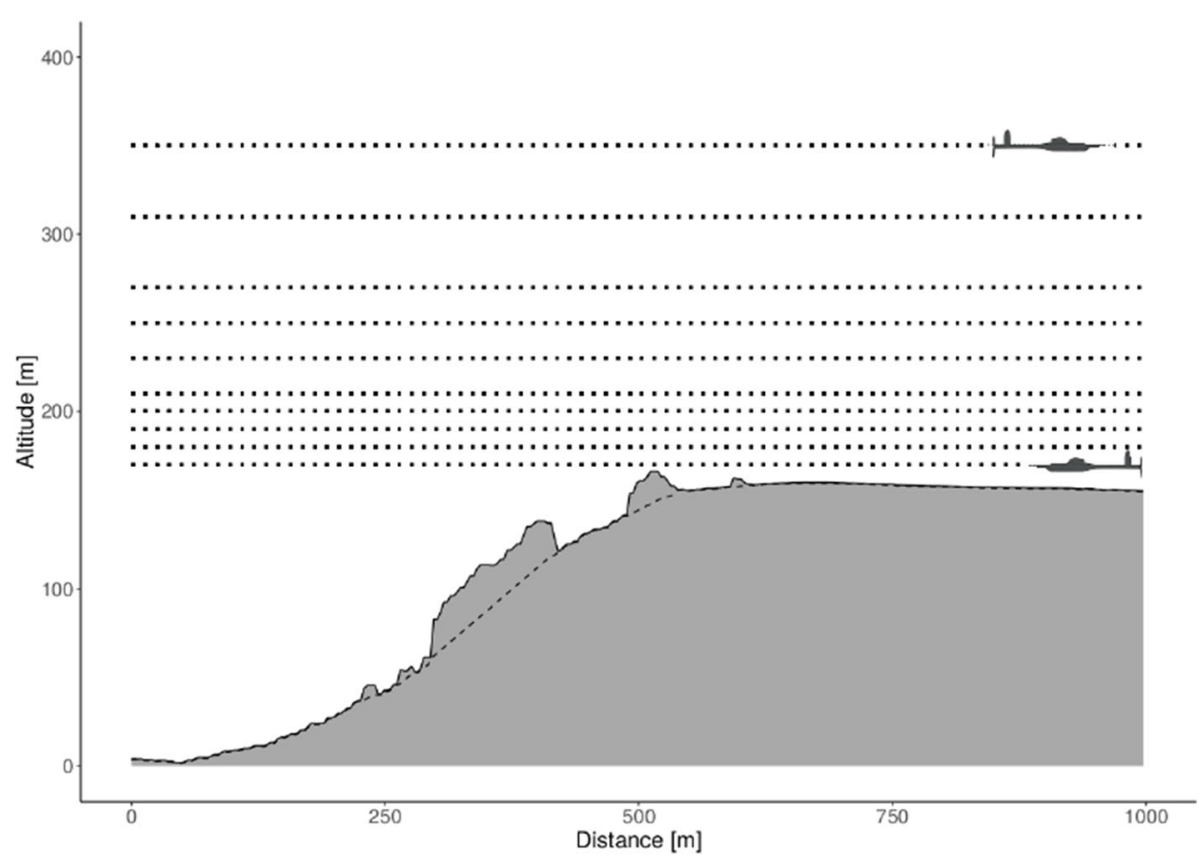

Fig. 3 Measurement strategy for the test site. Legs between 20 and $200 \mathrm{~m}$ with more legs flown in lower levels. Escarpment is facing west. The dashed line indicates the terrain without the trees

Table 1 Mean meteorological values and flight plan data for the flights on 21 and 22 September 2018

\begin{tabular}{lll}
\hline Name & Flight 1 & Flight 2 \\
\hline Date & $21 / 09 / 2018$ & $22 / 09 / 2018$ \\
Flight direction & East-west & East-west \\
Height [m] & $20-200$ & $20-200$ \\
Mean \# of legs per height & 4 & 4 \\
Mean wind dir. $\left[^{\circ}\right]$ & 259.3 & 275.2 \\
Mean wind speed[ $\left.\mathrm{m} \mathrm{s}^{-1}\right]$ & 9.79 & 4.44 \\
Mean temperature $\left[{ }^{\circ} \mathrm{C}\right]$ & 22.2 & 17.0 \\
Mean rel. humidity $[\%]$ & 42.8 & 40.4
\end{tabular}

Wind direction and speed averaged over all flown flight legs and all heights. Mean temperature and relative humidity at ground level

\subsection{Determination of Turbulence Parameters}

The wind and fast temperature data are logged at $500 \mathrm{~s}^{-1}$ and scaled down to $100 \mathrm{~s}^{-1}$ using a block mean. These raw $100 \mathrm{~s}^{-1}$ data are then processed using the inertial navigation system (INS) exact position data. The wind speed $\left|\mathbf{v}_{h}\right|$ is calculated by

$$
\left|\mathbf{v}_{h}\right|=\sqrt{u^{2}+v^{2}},
$$

using the two velocity components $u$ and $v$ generated by the post-processing software derived from the five-hole probe pressure sensors. In the end, one of the important variables for validating the impact of the escarpment on the flow is TKE, $k$, which is calculated by taking 
the velocity fluctuations from either the variance (Var) or the standard deviation $(\sigma)$ of all three wind components $(u, v$, and $w)$

$$
k=\frac{1}{2}\left(\operatorname{Var}_{u}+\operatorname{Var}_{u}+\operatorname{Var}_{w}\right)=\frac{1}{2}\left(\sigma_{u}^{2}+\sigma_{v}^{2}+\sigma_{w}^{2}\right) .
$$

The variance (Var) of a variable $X$ is calculated, using Reynolds decomposition where the fluctuations $X^{\prime}$ are separated from the mean $\bar{X}$, with

$$
\operatorname{Var}_{X}=\frac{1}{N-1} \sum_{i=1}^{N}\left(X_{i}-\bar{X}\right)^{2} .
$$

In order to set a proper averaging-window size $N$, we calculated the turbulent integral length scale $(L)$, i.e., a measure for the size of the largest turbulent eddies in the Kolmogorov inertial sub-range that contribute to the turbulent transport of momentum. The integral length scale, $L$, of a variable is determined by integration from zero lag to the first root at $\tau_{1}$ of the autocorrelation function $\rho$ and multiplied with the aircraft's mean true airspeed $\left|\overline{\mathbf{u}_{a}}\right|$ or the ground speed $\left|\overline{\mathbf{u}_{g}}\right|$. The integral length scale of $u$ using the mean true airspeed $\left|\overline{\mathbf{u}_{a}}\right|$, for example, is defined by

$$
L=\left|\overline{\mathbf{u}_{a}}\right| \int_{0}^{\tau_{1}} \rho_{u}(\tau) \mathrm{d} \tau
$$

An analysis of both flights presented in this paper showed a range of values for $L$ between 43 and $119 \mathrm{~m}$ for a single measurement height (see Table 2). The calculation was done for $L$ using the mean ground speed and the mean true airspeed per leg. In conditions with high wind speeds, the ground speed differs between upwind and downwind legs, whereas the mean true airspeed is independent from the wind speed and therefore less subject to fluctuations. To account for this behaviour and to find the maximum integral length scales, the calculation was done with both $\left|\overline{\mathbf{u}_{a}}\right|$ and $\left|\overline{\mathbf{u}_{g}}\right|$ of the UAS, seen in Table 2 . The difference in $L$ calculated with the ground speed and mean true airspeed is small for most heights. The biggest difference between those two is $28 \%$ at an altitude of $80 \mathrm{~m}$ on 21 September 2018. To account for all eddies present during the time of measurement, the window size for calculating $k$ was chosen to be larger than $119.3 \mathrm{~m}$, i.e., based on the highest $L$ calculated from both methods (see Table 2).

The variables mean wind speed $\mathbf{v}_{h}$, wind direction $\varphi$, TKE $k$, and inclination angle $\alpha$ shown in Sect. 4 are combined in a data frame after post-processing. The inclination angle is the angle between the horizontal plane in that height and the vertical direction of the wind hitting that plane. Flow coming from below the plane is considered positive while flow from above the plane is considered negative.

Having calculated the variables for the flight, it is possible to derive data for vertical profiles at certain positions over ground and to create a contour plot over the escarpment using interpolation between the horizontal data points. The interpolation method (Eq. 6) chosen for this analysis is the inverse distance weighted interpolation. It is widely used in spatial analysis and the Geographic Information System (Lu and Wong 2008). The principle of calculating the interpolated data points $a$

$$
a\left(x_{0}\right)=\frac{\sum_{i=1}^{N}\left(\frac{a\left(x_{i}\right)}{d\left(x_{0}, x_{i}\right)}\right)^{p}}{\sum_{i=1}^{N}\left(\frac{1}{d\left(x_{0}, x_{i}\right)}\right)^{p}},
$$




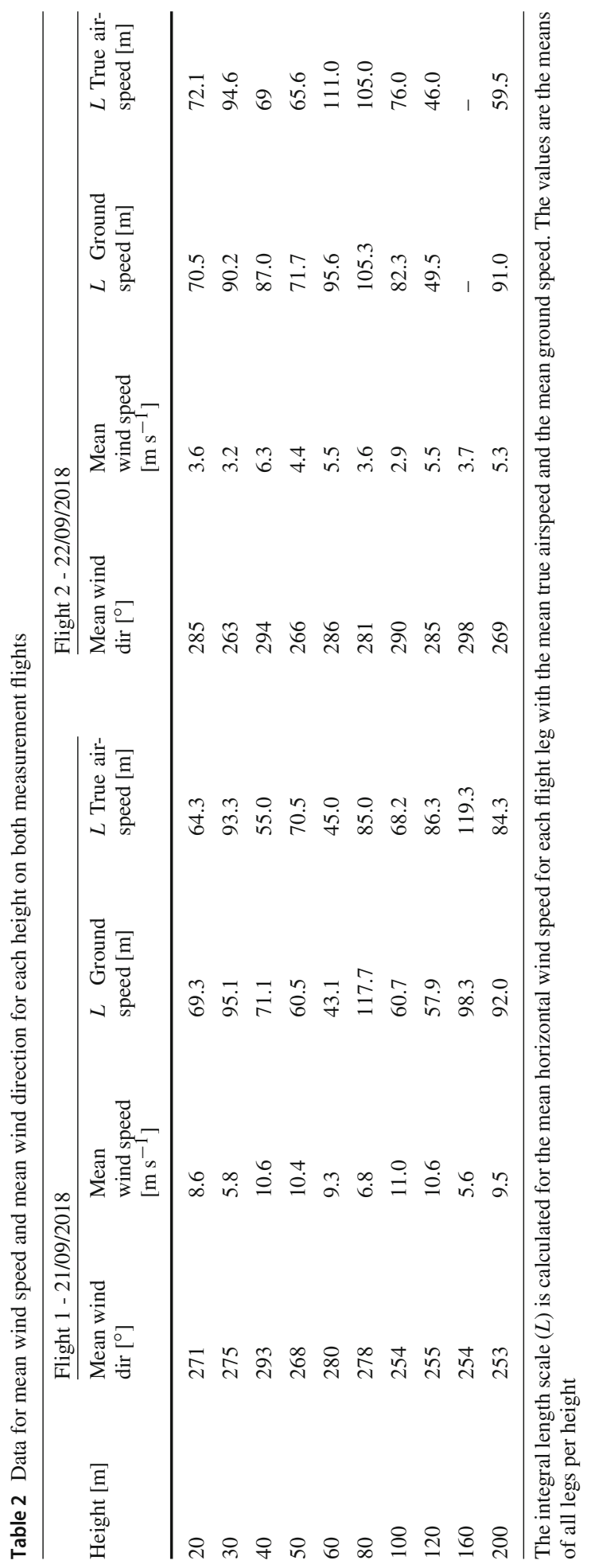


where $x_{i}$ is the reference point measured by the UAS, $x_{0}$ is the interpolated (arbitrary) point, and $d$ is the distance between the reference $x_{i}$, the arbitrary $x_{0}$ and the power parameter $p$. For $p$ approaching zero the impact of the direct neighbours onto the interpolated results reduces. A typical value for the power parameter is 2 , which has been chosen in this analysis.

\subsection{Tower Data}

The tower data presented in Sect. 4.1 were derived using $20 \mathrm{~s}^{-1}$ data from wind vanes and cup anemometers installed at $10,34,45,59,86$, and $100 \mathrm{~m}$ as well as Thies thermometers installed at 3, 23, 45, 72, and $96 \mathrm{~m}$. A block mean of $10 \mathrm{~min}$ was applied and faulty values were removed.

\subsection{Model Approach}

The goal of the model chain is to create a predictive simulation tool that is able to represent several ranges of atmospheric scales in a variety of complex terrains. Three numerical models are coupled: WRF (Skamarock et al. 2008), OpenFOAM (Weller et al. 1998), and FLOWer (Kroll et al. 1999).

The Advanced Research WRF (WRF-ARW) model, version 3.8.1, is used to simulate the flow over the test site and provide the first step of the model-chain. Our set-up is similar to Talbot et al. (2012), who used six model domains nested sequentially where the outer three model nests are run in URANS mode and the three innermost domains are run in LES mode. Due to considerations of computational cost, the sixth model domain has been removed. The innermost nest has a horizontal mesh size of $150 \mathrm{~m}$ and consists of $301 \times 301 \times 80$ data points. Vertical grid stretching is applied. The lowest model level is located at $10 \mathrm{~m}$ above the ground and $\Delta z$ close to the ground is $15 \mathrm{~m}$. The model top is defined as about $14.5 \mathrm{~km}$ above sea level. The Advanced Spaceborn Thermal Emission and Reflection Radiometer (ASTER) dataset (Schmugge et al. 2003) is used for the topography and the CORINE (Coordination of Information on the Environment) dataset from 2012 for the land-use categories. The initial and boundary conditions are provided by the ECMWF (European Centre for Medium-Range Weather Forecasts) operational analysis. The additional drag caused by trees is parametrized following the approach of Shaw and Schumann (1992). This is of particular importance given that the distance between the test site and the nearest forest is less than $100 \mathrm{~m}$.

The second step of the modelling chain is an OpenFOAM-based (version 6) CFD (computational fluid dynamics) model, which allows for further refinement of both vertical and horizontal resolution. The meso-microscale simulations are conducted with inflow conditions acquired from the WRF model, which stored the data along predefined borders at a 1-min interval. It provides data such as temperature, pressure, velocity, or humidity at the lateral and top boundaries of the meso-microscale domain $(10 \mathrm{~km} \times 10 \mathrm{~km} \times 2.5 \mathrm{~km})$. The meso-microscale model, implemented into the open source code OpenFOAM is based on an unsteady Reynolds-averaged Navier-Stokes approach. The transport equations for mass, momentum, and potential temperature are solved under the Boussinesq approximation, where density is only influenced by buoyancy forces. The turbulent equations are solved using a modified version of the standard $k-\epsilon$ model (El-Bahlouli et al. 2019). The $k-\epsilon$ model uses the TKE $k$ and its dissipation rate $\epsilon$.

The FLOWer simulation results from the third step are only available for a very short time frame of $10 \mathrm{~min}$ due to the computational efforts necessary. Hence, an explanation of the model and a comparison to the UAS data were not considered useful herein. 
Table 3 Measurement heights flown by MASC-3 for both days in September 2018

\begin{tabular}{llllllll}
\hline & \multicolumn{2}{l}{ Flight $1-21 / 09 / 2018$} & & \multicolumn{3}{l}{ Flight 2 - 22/09/2018 } \\
\cline { 2 - 3 } Altitude [m] & Start [UTC] & End [UTC] & $10-$ min file [UTC] & & Start [UTC] & End [UTC] & 10-min file [UTC] \\
\hline 20 & 1058 & 1104 & 1100 & 1324 & 1336 & 1330 \\
30 & 1106 & 1113 & 1110 & 1319 & 1323 & 1320 \\
40 & 1115 & 1120 & 1120 & 1311 & 1316 & 1320 \\
50 & 1136 & 1140 & 1140 & 1344 & 1350 & 1350 \\
60 & 1142 & 1148 & 1150 & 1305 & 1310 & 1310 \\
80 & 1151 & 1155 & 1200 & 1351 & 1357 & 1400 \\
100 & 1155 & 1204 & 1200 & 1257 & 1303 & 1300 \\
120 & 1204 & 1211 & 1210 & 1357 & 1404 & 1400 \\
160 & 1212 & 1218 & 1220 & 1404 & 1410 & 1410 \\
200 & 1219 & 1227 & 1230 & 1413 & 1416 & 1420
\end{tabular}

The columns 'Start' and 'End' are the times the UAS measured in a single height. The times in '10-min file' are the chosen 10-min files from the models for the comparison against the UAS data

To make a useful comparison between the measurements of the MASC-3 and the results by the first two model chain steps (WRF and OpenFOAM), it was necessary to align the 10-min mean model output data with the measurements from the 1.5-hr flight. To accomplish this, the flight data were split into altitude bins, each bin containing all flight legs of that altitude. Then the start and end time of each altitude bin were calculated in UTC. The model data were available as 10-min means, also in UTC. In the next step, the models 10-min file closest to the corresponding time of each altitude bin of the MASC-3 data was chosen. Table 3 gives an example on how the 10-min files where chosen for the flight on 21 September 2018. The 10-min files contain the values of the previous $10 \mathrm{~min}$.

In the next step, the altitude at which the MASC-3 was flying during that simulation timestep was extracted from the 10-min file (e.g., altitude $20 \mathrm{~m}$ from the 1100 UTC 10 -min file). To get the contour plots from model data in Sect. 4, the model data for each altitude were combined into a single data array to be interpolated and then plotted into a filled contour. The escarpment shape for the models does not show the trees, which makes it seem to be interpolated at different levels when in fact both the measurements and model data are interpolated on the same levels.

\section{Results}

In the first step, tower data are analyzed to ensure a quasi-steady situation i.e., to make sure there are no sudden variations (e.g., due to micro-fronts or similar events) in wind speed and direction during the flights. In Sect. 4.2, the UAS measurements for 21 and 22 September 2018 for different variables and a comparison to simulation results from the model chain are presented. 

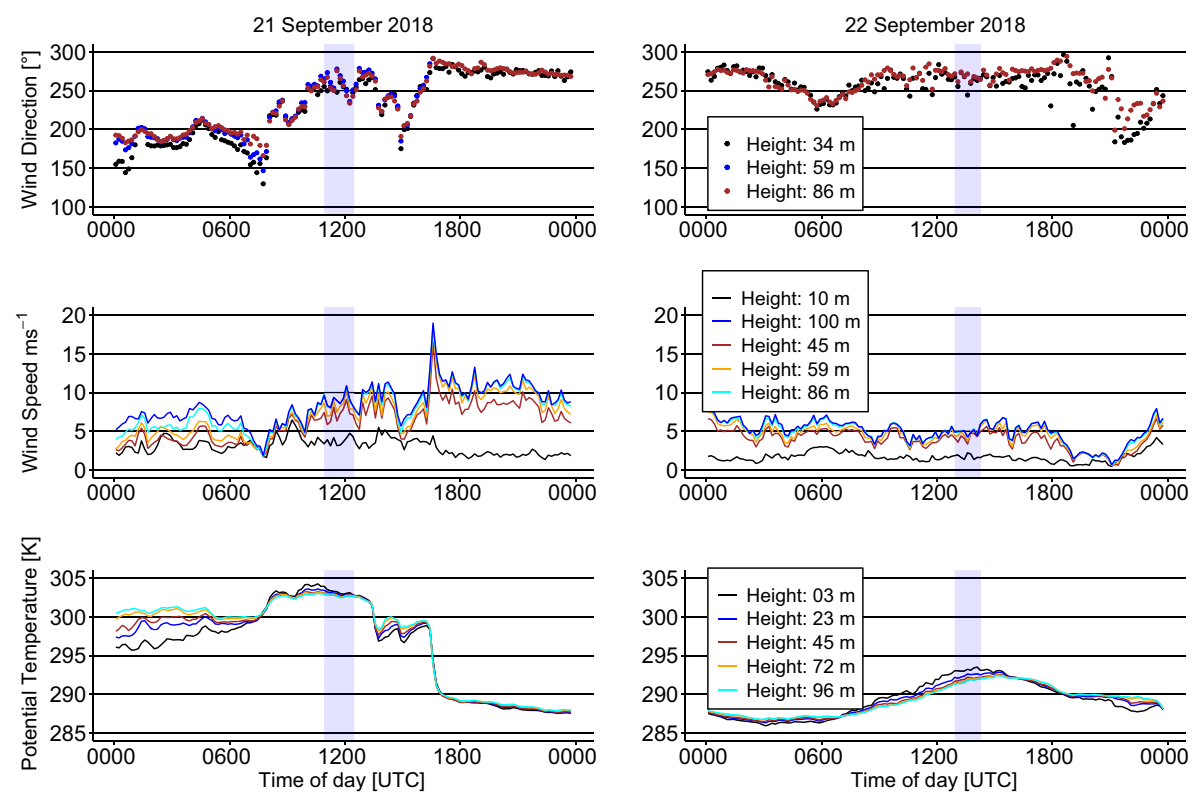

Fig. 4 Mean wind speed and wind direction (10, 34, 45, 59, 86, and $100 \mathrm{~m})$ measured by cup anemometer and wind vanes and a Thies thermometer $(3,23,45,72$, and $96 \mathrm{~m})$ mounted on the wind measurement mast close to the escarpment on 21 September and 22 September 2018. The blue vertically stretched rectangles indicate the flight duration of the UAS

\subsection{Diurnal Variations from Tower Data}

An overview of the diurnal variations at the test site for both days is presented in Fig. 4. The data originate from tower instrumentation located on site with measurement heights between 3 and $100 \mathrm{~m}$ a.g.l. and shown in UTC. On 21 September 2018, the atmosphere is stably stratified with the potential temperature increasing with height from $296 \mathrm{~K}$ in $3 \mathrm{~m}$ to $301 \mathrm{~K}$ in $96 \mathrm{~m}$. With mainly southern wind directions during this period, wind speed increases with height from $3-4 \mathrm{~m} \mathrm{~s}^{-1}$ at $10 \mathrm{~m}$ to around $8 \mathrm{~m} \mathrm{~s}^{-1}$ at $100 \mathrm{~m}$. At $0700 \mathrm{UTC}$, wind speed at all measurement heights decrease to a mutual point of about $2 \mathrm{~m} \mathrm{~s}^{-1}$.

After sunrise temperatures increase to $304 \mathrm{~K}$ close to the ground and $303 \mathrm{~K}$ in $96 \mathrm{~m}$ leading to a slightly unstable stratified atmosphere. The wind speed at all levels except the lowest are similar for the next hours, fluctuating between 6 and $12 \mathrm{~m} \mathrm{~s}^{-1}$. The wind direction changes slowly from south to west during that period. The passage of a cold front at 1630 UTC is marked by a sudden drop in temperature by $10 \mathrm{~K}$, a shift of the wind direction, and a sharp increase in wind speed. During the night, the atmosphere remains neutrally stratified as the wind speed remains above $6 \mathrm{~m} \mathrm{~s}^{-1}$ except for the lowest level. The next day began with westerly winds, wind speeds around $7 \mathrm{~m} \mathrm{~s}^{-1}$ and a neutral stratification. The wind speed is generally lower compared to the previous day and varies between 3 and $7 \mathrm{~m} \mathrm{~s}^{-1}$. The measurements at $10 \mathrm{~m}$ show wind speeds between 1 and $3 \mathrm{~m} \mathrm{~s}^{-1}$. The wind speed at $10 \mathrm{~m}$ above ground differs from measurements at greater heights due to a shadowing effect of the forest. In the early evening, as soon as the wind direction changes to south, the spread between the measurement heights becomes less significant and the wind speeds decrease. 
The time periods of the two flights are highlighted by a blue shade in Fig. 4. During the measurement flight on 21 September 2018, the wind direction varies between 260 and $275^{\circ}$, wind speeds fluctuate between 6 and $12 \mathrm{~m} \mathrm{~s}^{-1}$, and the atmospheric stratification is near neutral. The conditions on the next day are marked by a westerly wind at about $5 \mathrm{~m} \mathrm{~s}^{-1}$ and a slightly unstable atmosphere with potential temperature values of $293.5 \mathrm{~K}$ close to the ground and $292 \mathrm{~K}$ at $96 \mathrm{~m}$.

\subsection{Measurements and Model Data}

21 September 2018 was a mild day with temperatures slightly over $20^{\circ} \mathrm{C}$ and a mean westerly wind speed of $8.8 \mathrm{~m} \mathrm{~s}^{-1}$. On 22 September 2018 , the temperature was $5{ }^{\circ} \mathrm{C}$ lower with a mean westerly wind speed of $4.4 \mathrm{~m} \mathrm{~s}^{-1}$ (see Table 1).

The in situ data measured by the UAS and the results from the WRF and OpenFOAM models for 21 September 2018 are illustrated in Figs. 5, 7, 9, and 11, and those for 22 September 2018 in Figs. 6, 8, 10, and 12. To compare the measurements with the model results the approach explained in Sect. 3.4 was used.

For 21 September 2018 (Fig. 5a), the wind speed over the plateau varies from 3.5 to $14 \mathrm{~m} \mathrm{~s}^{-1}$. The wind maximum is established at a height of $250 \mathrm{~m}$ at a distance of $900 \mathrm{~m}$ to $1000 \mathrm{~m}$. At $200 \mathrm{~m}$ a.g.l. and a distance of $800 \mathrm{~m}$ is another area with higher wind speeds peaking at $10 \mathrm{~m} \mathrm{~s}^{-1}$. The wind speeds above $250 \mathrm{~m}$ vary from 4 to $8 \mathrm{~m} \mathrm{~s}^{-1}$ at a distance between 200 and $500 \mathrm{~m}$ and 8 to $12 \mathrm{~m} \mathrm{~s}^{-1}$ at 500 to $1000-\mathrm{m}$ distance. At the lee side of the tree tops, in the lowest $50 \mathrm{~m}$ a.g.l. along the plateau, the horizontal flow is decelerated. This is the area with the highest difference in wind speeds within a few metres vertical extent, ranging from 4 to $10 \mathrm{~m} \mathrm{~s}^{-1}$.

The measured wind speed on 22 September 2018 is illustrated by Fig. 6a. Wind speeds vary between 4 and $6 \mathrm{~m} \mathrm{~s}^{-1}$ in a stretch over the full extent of the plateau at heights of 210 to $240 \mathrm{~m}$. Below this strip, at the lee side of the trees, ranging vertically from 180 to $200 \mathrm{~m}$, lower wind speeds between 2 and $4 \mathrm{~m} \mathrm{~s}^{-1}$ occur. Another area with wind speeds between 2 and $4 \mathrm{~m} \mathrm{~s}^{-1}$ appears between 240 and $270 \mathrm{~m}$ in distance and between 500 and $1000 \mathrm{~m}$. The wind maximum of $8 \mathrm{~m} \mathrm{~s}^{-1}$ is established at a height of $360 \mathrm{~m}$ in a distance of $500 \mathrm{~m}$. The wind speeds above $250 \mathrm{~m}$ vary from 4 to $8 \mathrm{~m} \mathrm{~s}^{-1}$. The mean wind speed measured in the bottom left corner of the plotting plane fluctuates between 2 and $4 \mathrm{~m} \mathrm{~s}^{-1}$.

The model results for 21 September 2018 and 22 September 2018 are shown in Fig. 5b, c and Fig. 6b, c, respectively. The WRF model in Fig. 5b calculated a streak of wind speeds above $10 \mathrm{~m} \mathrm{~s}^{-1}$ at heights between 200 and $260 \mathrm{~m}$. Below $200 \mathrm{~m}$ height and at distances of more than $600 \mathrm{~m}$, the wind speed decreases to less than $5 \mathrm{~m} \mathrm{~s}^{-1}$. At a distance of less than $600 \mathrm{~m}$ the WRF simulation determines wind speeds between 6 and $10 \mathrm{~m} \mathrm{~s}^{-1}$. Above $260-\mathrm{m}$ altitude another small patch of wind speeds less than $10 \mathrm{~m} \mathrm{~s}^{-1}$ can be seen. Between 280 and $400 \mathrm{~m}$, with increasing distance, the wind speed decreases from $15 \mathrm{~m} \mathrm{~s}^{-1}$ to less than $10 \mathrm{~m} \mathrm{~s}^{-1}$.

The OpenFOAM model results for the horizontal wind speed illustrated in Fig. 5c shows an area of wind speeds in a range of $14 \mathrm{~m} \mathrm{~s}^{-1}$ to $16 \mathrm{~m} \mathrm{~s}^{-1}$ in $250 \mathrm{~m}$ altitude and a distance of 400 to $1100 \mathrm{~m}$. Another area with wind speeds around $15 \mathrm{~m} \mathrm{~s}^{-1}$ is located over the valley in a small band between 190 to $200 \mathrm{~m}$ and over the plateau between 180 and $220 \mathrm{~m}$ altitude. At distances between 100 and $850 \mathrm{~m}$ the wind speed decreases to less than $8 \mathrm{~m} \mathrm{~s}^{-1}$ in some regions close to the ground and at altitudes between 200 and $240 \mathrm{~m}$. The wind speed at heights above $260 \mathrm{~m}$ ranges between $8 \mathrm{~m} \mathrm{~s}^{-1}$ and $13 \mathrm{~m} \mathrm{~s}^{-1}$ with lower wind speeds towards the edges of the plot plane. 


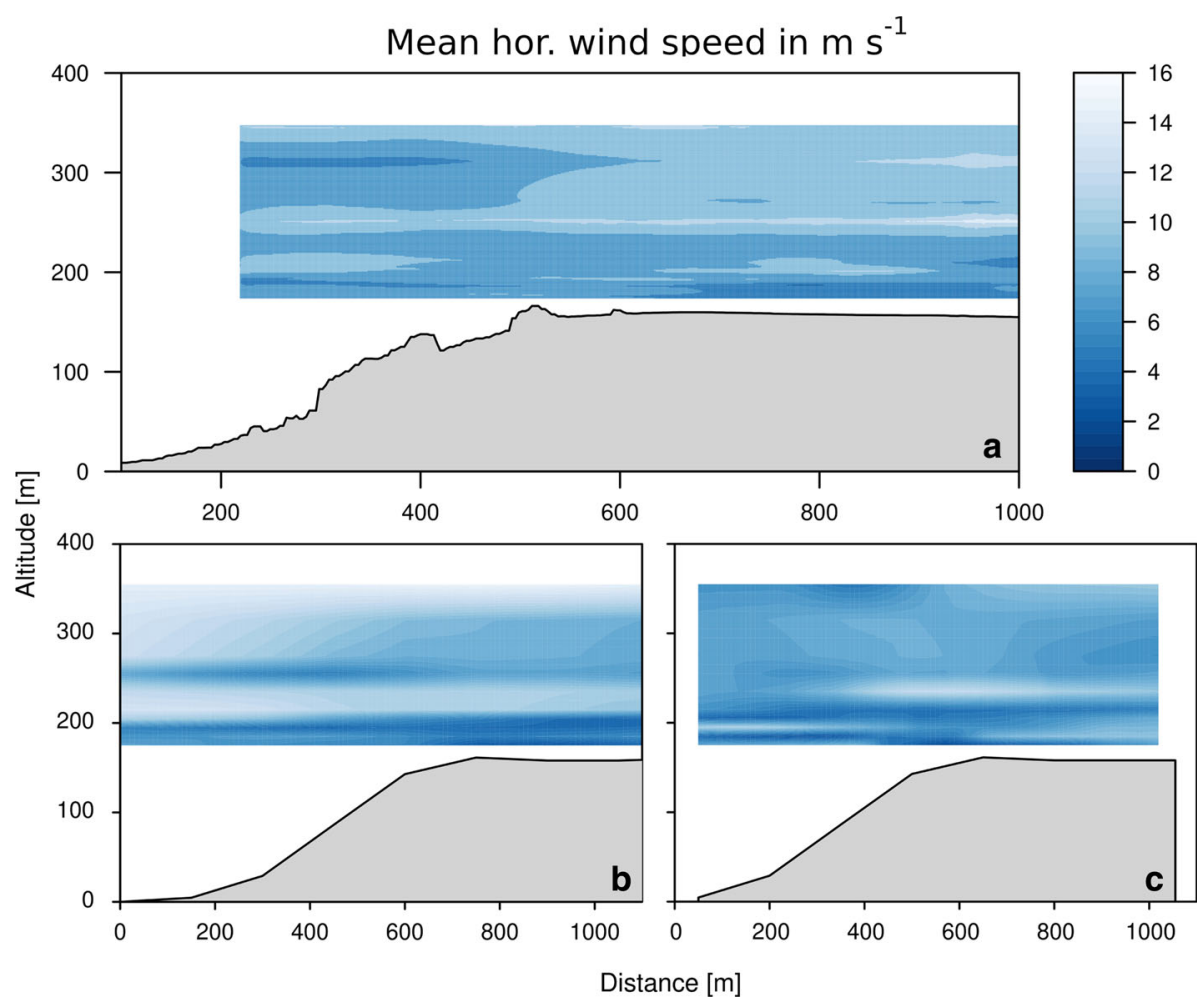

Fig. 5 MASC-3 measurement of the mean wind speed derived through interpolation from horizontal flight legs between 1055-1229 UTC (a) and the mean horizontal wind speed during the UAS flight time calculated by WRF (b) and OpenFOAM (c) models on 21 September 2018. The left side of the plot is facing west. Reference height of zero is at the bottom of the valley

For 22 September 2018 the WRF model in Fig. 6b estimated wind speeds between 1 and $6 \mathrm{~m} \mathrm{~s}^{-1}$ for altitudes between 180 and $250 \mathrm{~m}$. Above $250 \mathrm{~m}$ the wind speed increases to values of 6 to $8 \mathrm{~m} \mathrm{~s}^{-1}$. The lowest wind speeds of $3 \mathrm{~m} \mathrm{~s}^{-1}$ and less are located close to the ground above the plateau in distances between 800 and $1100 \mathrm{~m}$. Two more patches with wind speeds in the range of of 2 to $4 \mathrm{~m} \mathrm{~s}^{-1}$ were calculated in heights of 200 and $230 \mathrm{~m}$ and a distance between 0 and $600 \mathrm{~m}$.

The OpenFOAM model reported areas of wind speeds less than $3 \mathrm{~m} \mathrm{~s}^{-1}$ close to the ground above the plateau and at a height of $200 \mathrm{~m}$ and a distance of $200 \mathrm{~m}$. Patches of wind speeds above $6 \mathrm{~m} \mathrm{~s}^{-1}$ are shown in some areas beginning close to the ground over the escarpment at a distance of $400 \mathrm{~m}$. With increasing altitude, three more areas of wind speeds higher than $6 \mathrm{~m} \mathrm{~s}^{-1}$ can be seen. The most significant ones are at altitudes between 230 and $280 \mathrm{~m}$ and 300 and $350 \mathrm{~m}$. Between those two bigger areas of higher wind speeds a small stretch of wind speeds below $5 \mathrm{~m} \mathrm{~s}^{-1}$ was simulated.

For 21 September 2018, Fig. 7a shows a wind-direction change over the plateau from $265^{\circ}$ at $190 \mathrm{~m}$ to $235^{\circ}$ at $360 \mathrm{~m}$ above the surface. The strongest direction change appears directly over the escarpment with a difference of $60^{\circ}$ to the north between 190 and $270 \mathrm{~m}$ above ground. The change in wind direction is less distinct among distances of 700 to $1000 \mathrm{~m}$ with wind directions of $260^{\circ}$ instead of $285^{\circ}$ above the escarpment. 


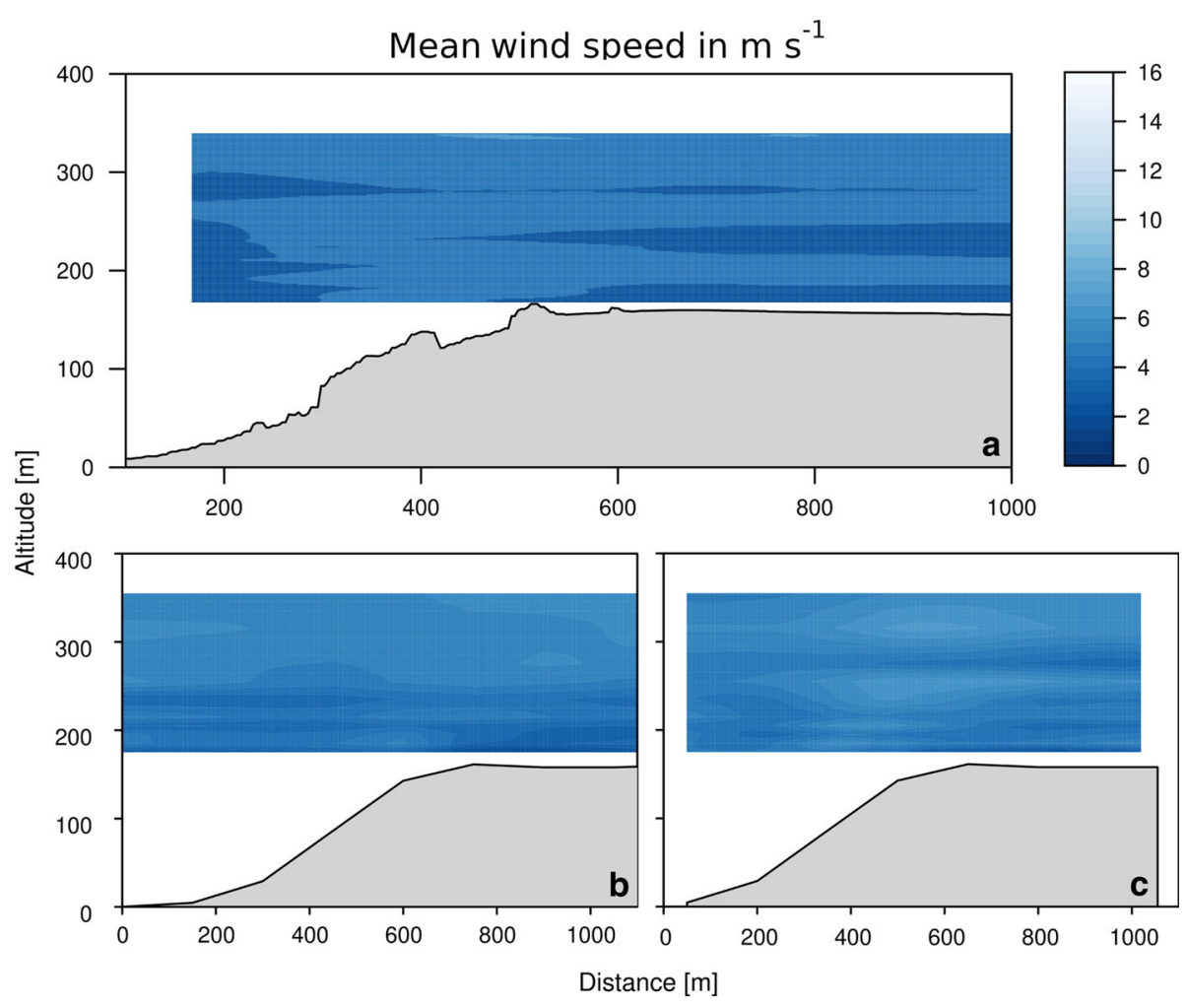

Fig. 6 MASC-3 measurement of the mean wind speed derived through interpolation from horizontal flight legs between 1255-1417 UTC (a) and the mean horizontal wind speed during the UAS flight time calculated by WRF (b) and OpenFOAM (c) models on 22 September 2018. The left side of the plot is facing west. Reference height of zero is at the bottom of the valley

The overall mean wind direction on the 22 September 2018 was $282^{\circ}$, which is $20^{\circ}$ different to the measurement on 21 September 2018. The wind direction immediately above the escarpment varies between $280^{\circ}$ and $320^{\circ}$, while most of the wind directions in the measured area are within $280^{\circ}$. Another small patch and a larger area with directions beyond $280^{\circ}$ occur close to the ground in distances between 650 and $800 \mathrm{~m}$ and in heights of 170 to $200 \mathrm{~m}$ above the escarpment, respectively.

The WRF model in Fig. $7 \mathrm{~b}$ shows two areas with a wind direction of up to $290^{\circ}$. The area with a stronger change in wind direction compared to the surrounding area is located at an altitude of $200 \mathrm{~m}$ over the escarpment edge in a distance of 500 to $900 \mathrm{~m}$. The second area with a stronger change in wind direction is positioned higher aloft at 240 to $290 \mathrm{~m}$ altitude.

The OpenFOAM model shows two areas of wind directions towards $220^{\circ}$ at an altitude of $190 \mathrm{~m}$ on both ends of the plot plane. Underlying, close to the ground, a wind shear from $220^{\circ}$ to more than $260^{\circ}$ is visible. Above $220 \mathrm{~m}$ the wind direction changes to nearly $280^{\circ}$ and back to less than $250^{\circ}$ at $350-\mathrm{m}$ altitude.

On 22 September 2018 (Fig. 8b, c) both models predict the wind direction between $280^{\circ}$ and $300^{\circ}$. The WRF model, in Fig. 8b, calculated a wind direction exceeding $300^{\circ}$ in some small areas above the top edge of the escarpment and the plateau. Approaching the escarpment in distances between 0 and $400 \mathrm{~m}$ and heights in the range of 250 to $360 \mathrm{~m}$, the wind direction 


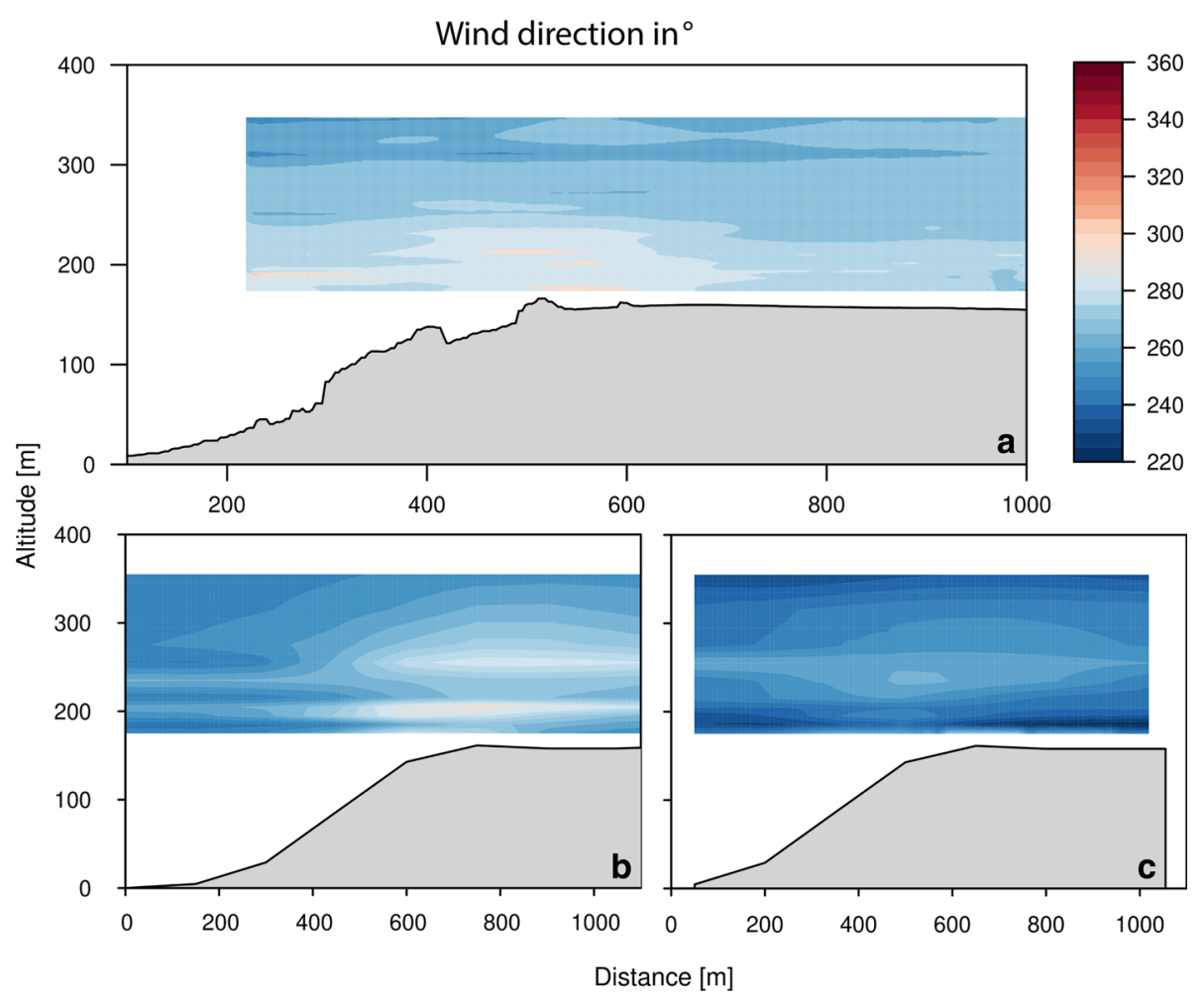

Fig. 7 MASC-3 measurement of the wind direction derived through interpolation from horizontal flight legs between 1055-1229 UTC (a) and the mean wind speed during the UAS flight time calculated by WRF (b) and OpenFOAM (c) models on 21 September 2018. The left side of the plot is facing west. Reference height of zero is at the bottom of the valley

changes from $300^{\circ}$ to $280^{\circ}$. This change in wind direction is less distinct in the OpenFOAM model results. Figure $8 \mathrm{c}$ shows three thin areas of wind direction around $260^{\circ}$. Two of those are located at heights just below and above $200 \mathrm{~m}$ in distances between 100 and $550 \mathrm{~m}$. The third stretch is positioned over the escarpment top in an altitude of $180 \mathrm{~m}$. Apart from a large area at altitudes between 250 and $340 \mathrm{~m}$ with a wind direction of $290^{\circ}$, only a small area between 100 and $400 \mathrm{~m}$ distance and a height of 180 to $190 \mathrm{~m}$ shows wind directions of more than $300^{\circ}$.

The TKE (Fig. 9a) during the time of measurement on 21 September 2018 reaches maximum values of $14 \mathrm{~m}^{2} \mathrm{~s}^{-2}$ behind the escarpment and close to the ground. Other areas with values higher than $4 \mathrm{~m}^{2} \mathrm{~s}^{-2}$ can be found at heights of 260 to $300 \mathrm{~m}$ above ground in a distance 600 to 800 and over the escarpment at a distance of 300 to $500 \mathrm{~m}$ and a height of $200 \mathrm{~m}$ above the plateau ground level. The latter reaches values of 10 to $14 \mathrm{~m}^{2} \mathrm{~s}^{-2}$. The TKE within the other regions varies between 0 and $4 \mathrm{~m}^{2} \mathrm{~s}^{-2}$. The long vertical stretch of very low TKE values close to $0 \mathrm{~m}^{2} \mathrm{~s}^{-2}$ at the right border are a result of a boundary-value problem within the interpolation.

The TKE (Fig. 10a) during the time of measurement on 22 September 2018 reaches maximum values between 7 and $8 \mathrm{~m}^{2} \mathrm{~s}^{-2}$ close to the plateau ground in the lee area of the trees in distances of up to $700 \mathrm{~m}$. The vertical extent of this stretch is up to $230 \mathrm{~m}$ above 


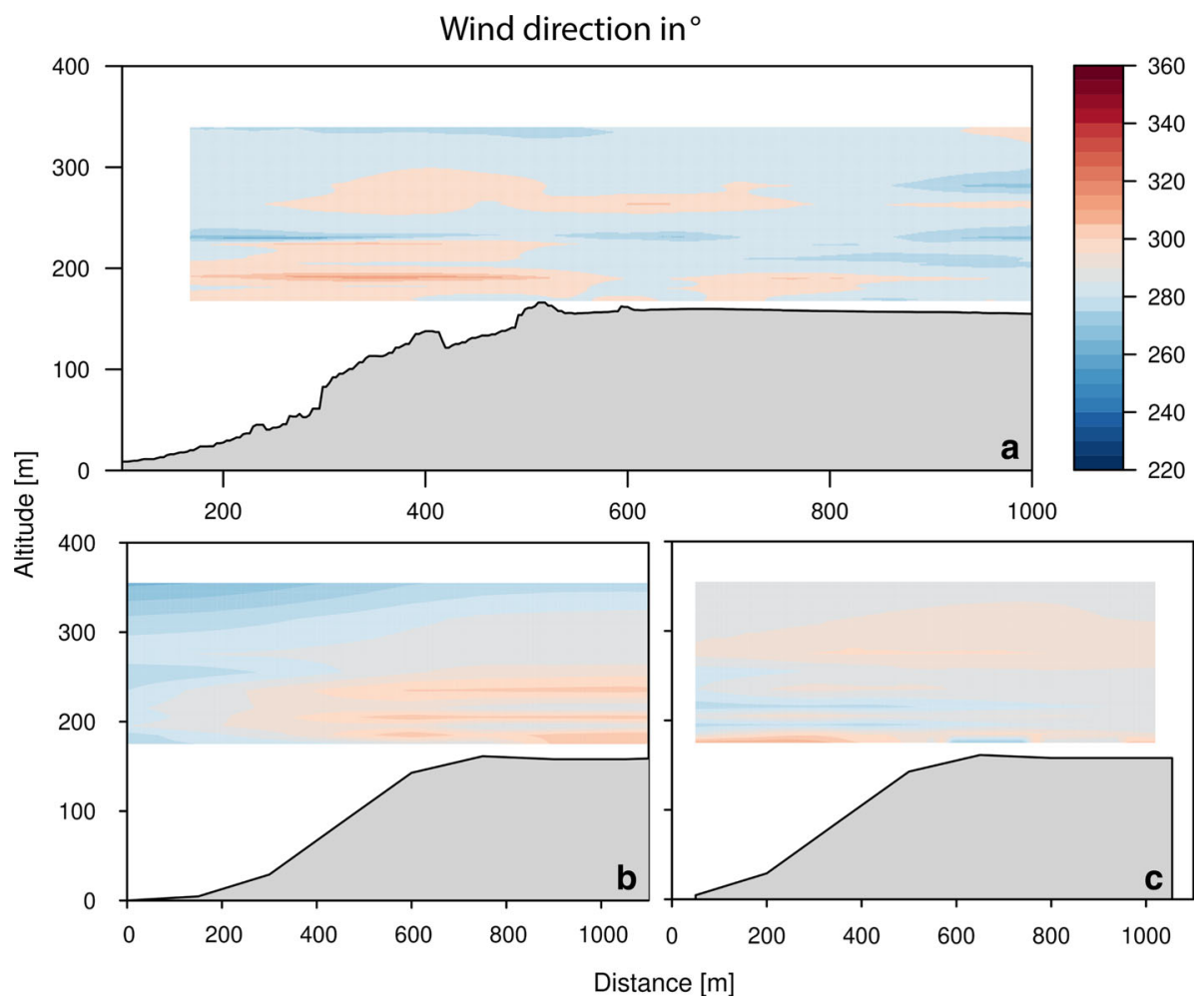

Fig. 8 MASC-3 measurement of the wind direction derived through interpolation from horizontal flight legs between 1255-1417 UTC (a) and the mean wind speed during the UAS flight time calculated by WRF (b) and OpenFOAM (c) models on the 22 September 2018. The left side of the plot is facing west. Reference height of zero is at the bottom of the valley

ground. In other areas $k$ peaks at $2 \mathrm{~m}^{2} \mathrm{~s}^{-2}$ with small patches of values up to $4 \mathrm{~m}^{2} \mathrm{~s}^{-2}$. In the trees' lee the TKE is up to three times higher compared to the undisturbed flow in front of the escarpment.

Model results for both days are shown in Figs. 9b, c and 10b, c for 21 September 2018 and 22 September 2018, respectively. The WRF model for 21 September 2018 in Fig. 9b calculated values for the TKE between 0 and $5 \mathrm{~m}^{2} \mathrm{~s}^{-2}$, with the highest values close to $5 \mathrm{~m}^{2} \mathrm{~s}^{-2}$ in a stretch along the plot at a height of $200 \mathrm{~m}$ and a larger area between 0 and $550 \mathrm{~m}$ distance and altitudes at a range of 240 to $280 \mathrm{~m}$. The lowest $20 \mathrm{~m}$ of the plotted data in front of the escarpment show values of less than $2 \mathrm{~m}^{2} \mathrm{~s}^{-2}$ for $k$ while the TKE over the plateau is higher with values reaching $3 \mathrm{~m}^{2} \mathrm{~s}^{-2}$. The upper left part of the plotting plane also shows TKE close to zero.

The OpenFOAM model in Fig. 9c calculated the TKE of 6 to $8 \mathrm{~m}^{2} \mathrm{~s}^{-2}$ for the bottom half of the plotting area, with an exception for the lowest $30 \mathrm{~m}$ above the plateau, where the TKE is below $2 \mathrm{~m}^{2} \mathrm{~s}^{-2}$. The upper half of the plotted data shows an increase in $k$ with distance from left to right.

On 22 September 2018 the TKE modelled by the WRF model shows values of near $0 \mathrm{~m}^{2} \mathrm{~s}^{-2}$ for most of the plot. Only a small patch in $280 \mathrm{~m}$ height and $400 \mathrm{~m}$ distance together with an area above the plateau and the top of the escarpment has a TKE between 2 and $4 \mathrm{~m}^{2} \mathrm{~s}^{-2}$. 


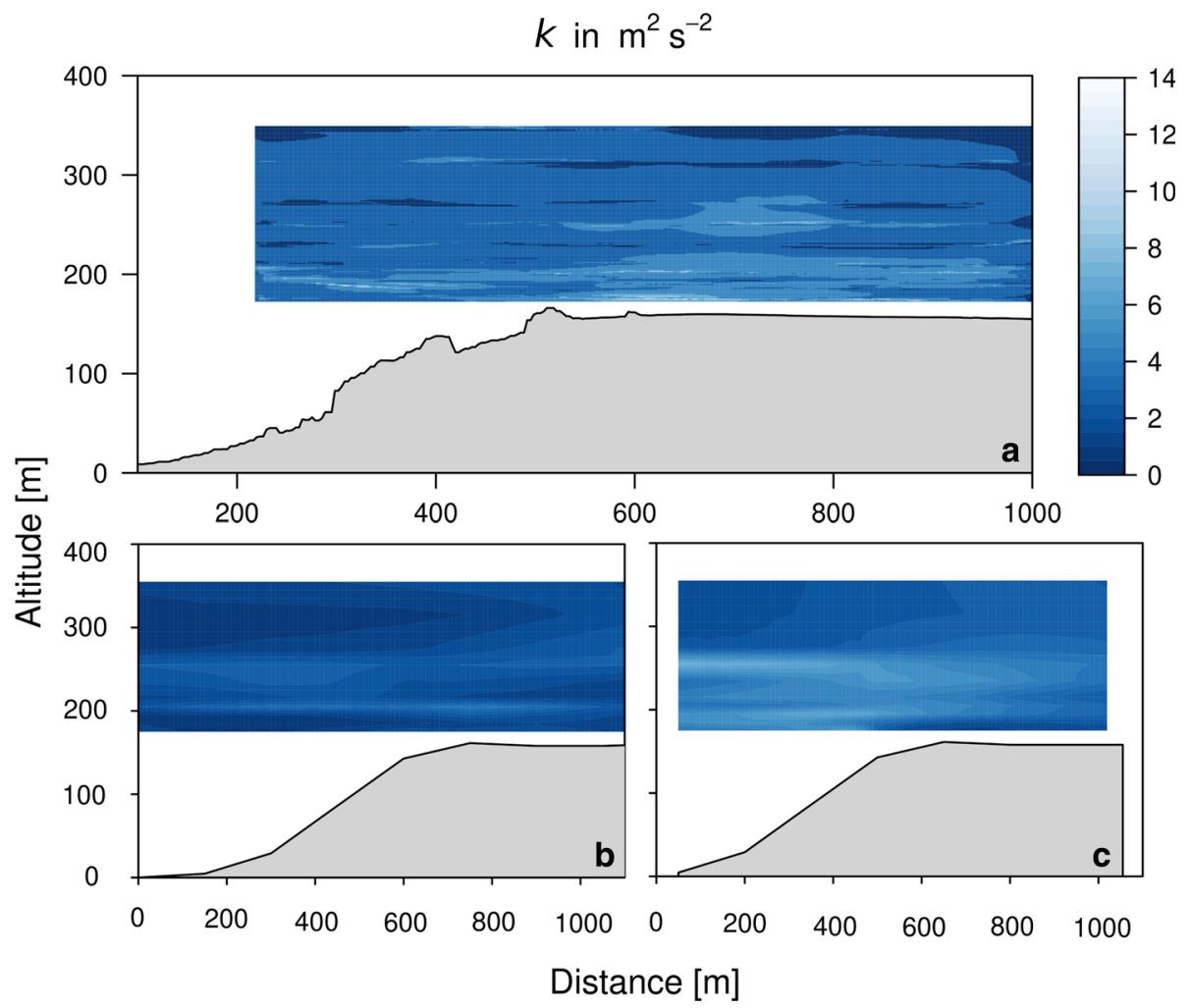

Fig. 9 MASC-3 measurement of the TKE derived through interpolation from horizontal flight legs between 1055-1229 UTC (a) and the mean wind speed during the UAS flight time calculated by WRF (b) and OpenFOAM (c) models on 21 September 2018. The left side of the plot is facing west. Reference height of zero is at the bottom of the valley

The OpenFOAM model in Fig. 10c is again divided in an upper and bottom part. The bottom half of the plot shows a TKE of $2 \mathrm{~m}^{2} \mathrm{~s}^{-2}$ with an area of nearly $4 \mathrm{~m}^{2} \mathrm{~s}^{-2}$ at a distance between 400 and $700 \mathrm{~m}$ and altitudes ranging from 180 to $270 \mathrm{~m}$. In the upper half, $k$ reaches maximum values of $1 \mathrm{~m}^{2} \mathrm{~s}^{-2}$.

The change in inclination angle for 21 September 2018 is shown in Fig. 11a. Over the escarpment positive inclination angles of up to $20^{\circ}$ are visible at heights between 190 and $260 \mathrm{~m}$. The inclination angle over the plateau varies between $0^{\circ}$ and $10^{\circ}$ with a few spots of angles towards $-10^{\circ}$. In an area in a distance of 700 to $1000 \mathrm{~m}$ and a height above ground of 230 to $250 \mathrm{~m}$, negative inclination angles of up to $-10^{\circ}$ are established.

The change in inclination angle for 22 September 2018 is shown in Fig. 12a. Over the escarpment, positive inclination angles of up to $20^{\circ}$ are visible in heights between 190 and $250 \mathrm{~m}$. The inclination angle over the plateau varies between $0^{\circ}$ and $-10^{\circ}$ with a few spots of angles towards $-20^{\circ}$ at a distance of $1000 \mathrm{~m}$. In general a positive inclination was measured over the escarpment, while the inclination angles above the plateau are mostly negative. 


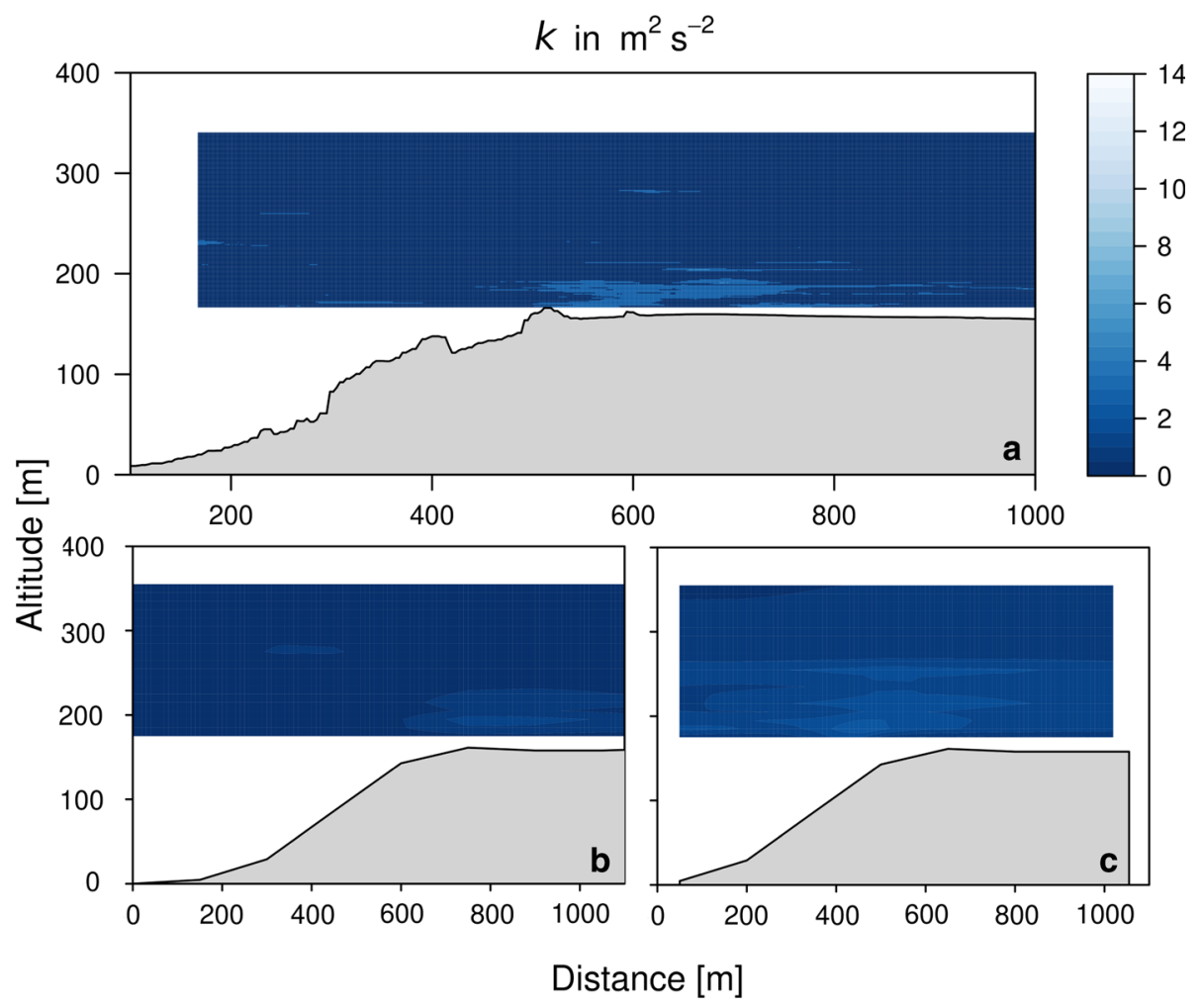

Fig. 10 MASC-3 measurement of the TKE derived through interpolation from horizontal flight legs between 1255-1417 UTC (a) and the mean wind speed during the UAS flight time calculated by WRF (b) and OpenFOAM (c) models on 22 September 2018. The left side of the plot is facing west. Reference height of zero is at the bottom of the valley

Figure 11b shows the WRF results for the inclination angle on 21 September 2018. At a distance of $600 \mathrm{~m}$, above the escarpment top, the plot indicates an upward motion with an inclination of up to $20^{\circ}$. This positive inclination angle can also be seen in another patch $50 \mathrm{~m}$ aloft. Between altitudes of 180 and $240 \mathrm{~m}$ a negative inclination angle of nearly $-10^{\circ}$ is visible.

The OpenFOAM model simulated a similar picture with smaller positive and negative changes in the inclination angle. A positive inclination angle of $10^{\circ}$ to $20^{\circ}$ can be seen in altitudes between 180 and $230 \mathrm{~m}$ in a distance of 300 to $400 \mathrm{~m}$. The area with negative inclination angles reaching $-6^{\circ}$ over the plateau is extended over the whole plateau.

For 22 September 2018 the inclination angle in Fig. 12b, c is more distinct compared to the first day. Negative inclination of up to $-10^{\circ}$, and therefore indicating a downward motion, can be seen above the plateau in distances between 700 and $1100 \mathrm{~m}$. The location of positive inclination angles calculated by the WRF model is again above the upper part of the escarpment reaching onto the plateau. Below $200 \mathrm{~m}$ the inclination angle reaches more than $20^{\circ}$ and therefore its highest positive value. The positive angle is then changing to $0^{\circ}$ at $360 \mathrm{~m}$ altitude. At a distance of $900 \mathrm{~m}$ the inclination angle has negative values of up to $-10^{\circ}$ at $300 \mathrm{~m}$ altitude. 


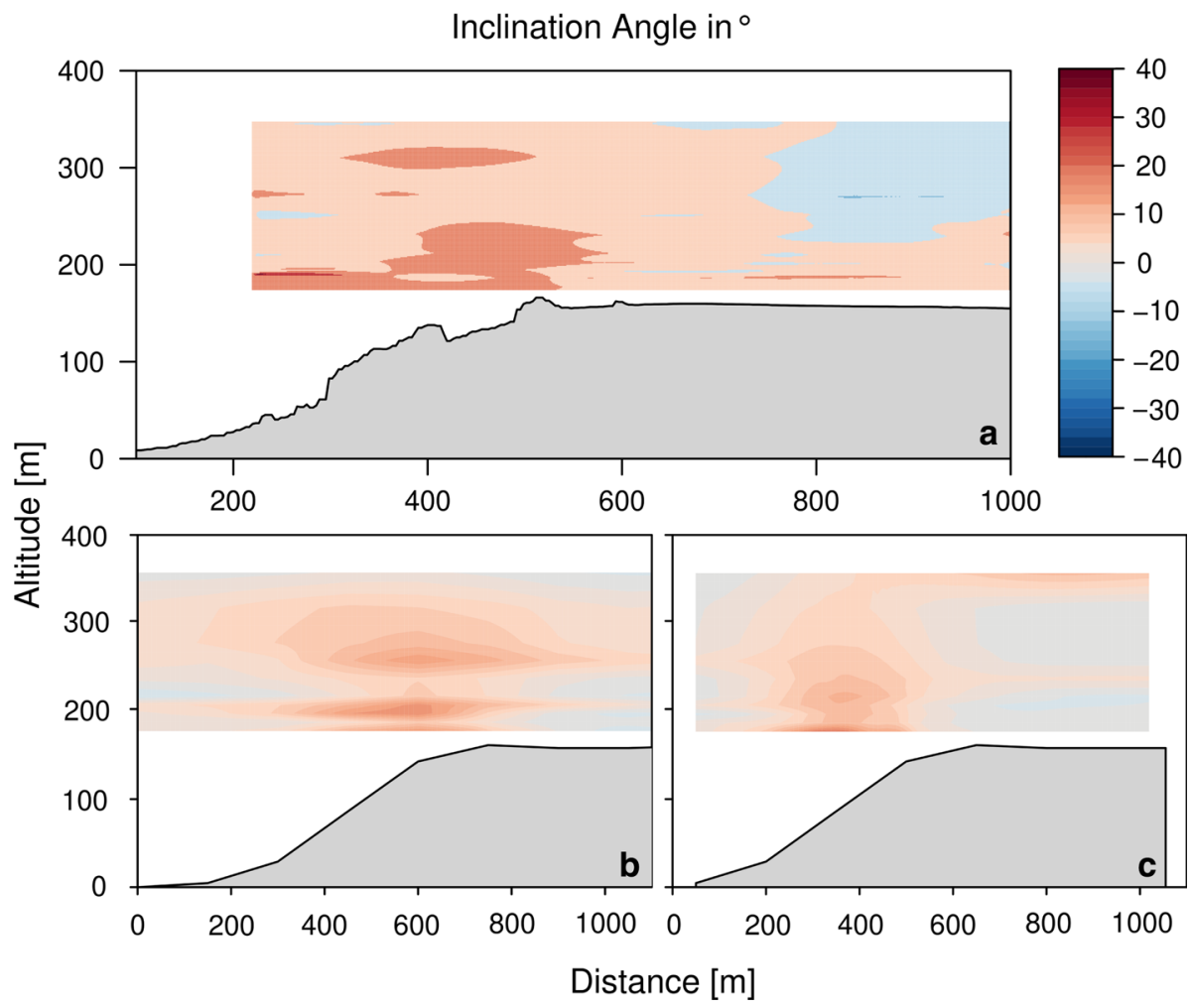

Fig. 11 MASC-3 measurement of the inclination angle derived through interpolation from horizontal flight legs between 1055-1229 UTC (a) and the mean wind speed during the UAS flight time calculated by WRF (b) and OpenFOAM (c) models on 21 September 2018. The left side of the plot is facing west. Reference height of zero is at the bottom of the valley

The location of positive inclination angles from the OpenFOAM model is located at the same spot over the escarpment compared to 21 September 2018. The positive inclination for 22 September 2018 reaches more than $20^{\circ}$ in altitudes of 190 to $220 \mathrm{~m}$. With height the inclination angle changes towards $5^{\circ}$, not reaching a neutral position within the plot plane. 


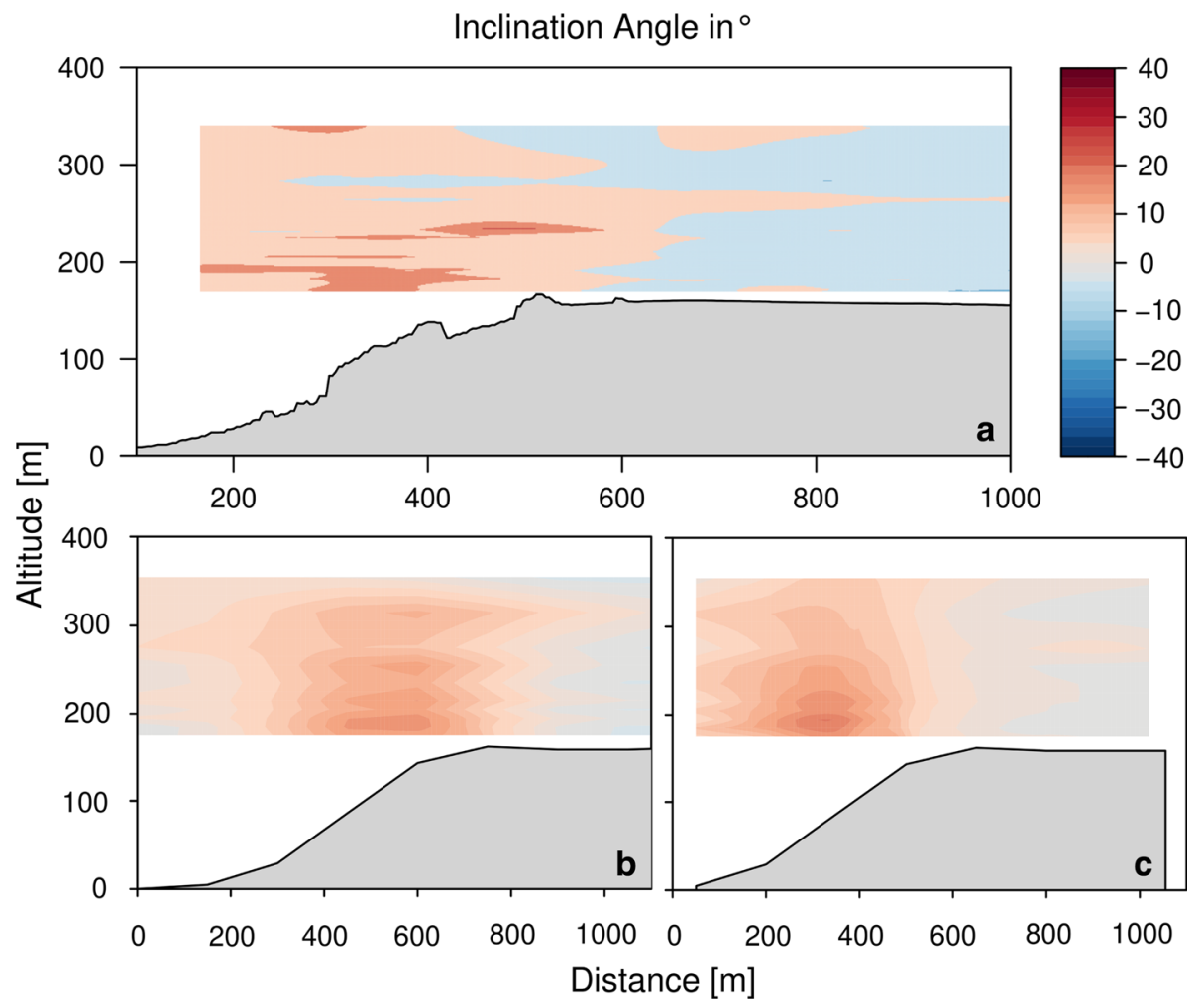

Fig. 12 MASC-3 measurement of the inclination angle derived through interpolation from horizontal flight legs between 1255-1417 UTC (a) and the mean wind speed during the UAS flight time calculated by WRF (b) and OpenFOAM (c) models on 22 September 2018. The left side of the plot is facing west. Reference height of zero is at the bottom of the valley

\section{Discussion}

\subsection{Wind-Field Measurements}

This subsection discusses the results from MASC-3. Independent of the different wind speeds, the results obtained from airborne in situ measurements and models presented above show similar flow features for two different days. Heights between 20 and $200 \mathrm{~m}$ above the plateau, relevant for the installation and operation of the wind energy converters in their planned locations, were covered. A Bernoulli-like effect of an accelerated flow over an obstacle is expected in regions with complex terrain (Belcher et al. 2012). Such behaviour was observed on both days. The flow accelerated in areas beginning at the top of the escarpment along the plateau in heights between 40 and $80 \mathrm{~m}$ above ground. Below and above those areas are zones with reduced wind speeds. In the lee of the trees the wind speed continues to decrease. How distinctive these areas are depends on the mean wind speed and the wind direction. For westerly wind directions the path to overcome the escarpment is $60-80 \%$ shorter compared to a flow from the north-west or south-west (Fig. 1). The longer path through the forested escarpment removes energy from the flow, which results in a stronger deceleration in the lee of the trees. Figures $7 \mathrm{a}$ and $8 \mathrm{a}$ show a wind direction change of more than $20^{\circ}$ from 
western towards northern winds. This change is a possible result of a channeling flow along the escarpment southward.

After a certain distance we would expect to see a recirculation zone between the accelerated flow due to the escarpment and the decelerated area below (Berg et al. 2011). This phenomena describes a detachment of the flow above the trailing edge of the escarpment and a reattachment (i.e., a downward motion) further downstream the plateau. The distance from the trailing edge where this downward motion happens depends on multiple factors like the shape and height of the obstacle and the speed and direction of the flow (Berg et al. 2011). For 21 September 2018 (Fig. 5a), we see an area at the right end of the plot at a distance of $1000 \mathrm{~m}$ that could be the beginning of the flow recirculation. For 22 September 2018 (Fig. 6a), with lower general wind speeds, a recirculation zone would be expected closer to the escarpment, but there is no indication of increased momentum towards the ground. Due to the low wind speeds and the less distinct difference between the areas of accelerated and decelerated flow, a recirculation zone might not be present. Menke et al. (2019) found that during the Perdig $\tilde{a}$ o experiment recirculation zones mostly developed in conditions of mean wind speeds $>8 \mathrm{~m} \mathrm{~s}^{-1}$

Neutral to negative angles above the plateau on both days indicate a downward movement, which facilitates the formation of a recirculation zone over the plateau. However, this conclusion is ambiguous, because Figs. 11a and 12a could as well be interpreted to show the tendency of the flow detaching without recirculating towards the ground. A previous study (Wildmann et al. 2017) used the previous version of MASC over the same area, obtained similar results, but at that time it was not possible to measure below $60 \mathrm{~m}$ above the plateau. This gap was filled by using the MASC-3, flying as low as the tree tops covering the upper edge of the escarpment, to show that at canopy height the highest turbulence, generated by the forest, was measured. Another small patch of high TKE has been measured on 21 September 2018 in a distance of $300 \mathrm{~m}$ above the escarpment (see Fig. 9a). If a free-flowing atmosphere west of the escarpment is considered, values that high are not expected. One possible explanation is the presence of the single hill upstream (Fig. 1) causing a disturbance and turbulence.

For both days it is difficult to distinguish between an orographically-forced acceleration of the flow and the impact of the stratification (Fig. 4). The air close to the ground was warmer than the air aloft. The difference in potential temperature with height is small, which has an effect on air masses being lifted vertically, but the impact of the escarpment in these cases should be considerably higher.

Despite the large difference in wind speed between the two days, atmospheric phenomena like acceleration of the flow with a recirculation zone over the plateau, the difference in inclination angle above the escarpment and the plateau, and high TKE values downstream of the trees were captured by MASC-3. High TKE close to the ground and along the plateau, together with the inclination angles, and the wind shear along the rotor plane found in similar locations are important factors to improve the modelling efforts for wind-field simulations in complex terrain, especially to resolve the TKE in the lee of the trees for different occurrences, as this directly impacts the fatigue loads onto wind turbines placed in such locations.

In the past, studies by Emeis et al. (1995), Berg et al. (2011), and Lange et al. (2016) investigated the effect of escarpments on flows. The study by Emeis et al. (1995) showed similar features over a smaller escarpment in Hjardemal, Denmark. The study used 18 measurement masts equipped with cup and sonic anemometers between 5 and $10 \mathrm{~m}$ above ground, upstream and downstream of a 16-m high escarpment. A speed-up over the crest was measured for three different thermal stratifications. The results look similar to the measurements conducted in the present study. A small internal boundary layer formed right behind the top of the escarpment. The studies by Berg et al. (2011) and Lange et al. (2016) were both carried 
out at the Bolund test site in Denmark. Berg et al. (2011) found a speed-up of 30\% over the top of the escarpment and a maximum enhancement of the turbulence intensity of $300 \%$ compared to the undisturbed flow in front of the escarpment. A key difference to the present study is the forested escarpment. The effect of trees onto the flow was not investigated in any of these studies. Emeis et al. (1995) also found an impact of the escarpment on the upstream flow and its properties as far down as $400 \mathrm{~m}$. This effect could not be investigated with the measurement set-up in the present study, but should be considered for future measurements. An effect of the escarpment on the wind direction itself was found, but no indications of the wind direction influencing the wake characteristics like TKE and wake length behind the escarpment.

To analyze small turbulent structures and the wind field in more detail, Berg et al. (2011) proposed a measurement approach with a higher temporal and especially a higher spatial resolution by using scanning lidars instead or additionally using masts in fixed locations and heights. This study adds to an approach with UAS providing measurements with high spatial and temporal resolution over a large area of the flow moving over an escarpment and thus is a good tool to validate and improve models in complex terrain.

\subsection{Comparison with the Model Chain}

To validate the numerical model chain for flow simulation over the escarpment and along the future wind turbines, MASC-3 data from 21 and 22 September 2018 were compared with simulations for the first two model steps (WRF and OpenFOAM).

The coarse WRF model simulation as well as the finer OpenFOAM model are in agreement with the UAS measurements. In particular the inclination angle in Fig. 11b, c and Fig. 12b, $\mathrm{c}$ and the mean horizontal wind Figs. 5b, $\mathrm{c}$ and $6 \mathrm{~b}$, c give promising results when compared with the measurements and are capable of modelling local phenomena such as over-speeding and small changes in inclination angle in complex terrain. The OpenFOAM model predicted the speed-up over the escarpment at similar locations as the MASC-3. These locations are as well in agreement with past research by Emeis et al. (1995) and Chow and Street (2009). The area of higher wind speeds calculated by the WRF model starts at a similar distance, but is located in lower altitudes.

The WRF model is the first step in the model chain and serves as input for the OpenFOAM model. Naturally the OpenFOAM model should be in better agreement with measurements and literature than the WRF model. For the inclination angle (a proxy for the vertical velocity) both models (Fig. 12b, c) gave results in good agreement with the measurements. In small areas above the escarpment the OpenFOAM model performs slightly better. Features like the turnover point from positive to negative inclination angles at $600 \mathrm{~m}$ distance were captured by the OpenFOAM model while WRF shows a stronger upward flow at that location. Emeis et al. (1995) also showed the highest vertical velocity close to the top of the escarpment.

The calculations for the TKE and the wind direction need to be adjusted (e.g., using a more detailed implementation of the forest as the main source for turbulence production close to the ground) to be in a better agreement with the measurement and most importantly to make the simulations a trusted tool for site assessment for wind turbines in complex terrain. Berg et al. (2011) found that RANS models, due to their spatial structure, are not ideal to simulate small-scale turbulence in complex terrain. This problem might be intensified by the trees and the additional turbulence introduced by them. Both models parametrize trees on the escarpment in their predictions, but do not use the exact distribution of forest patches along the cross-section. Large-eddy simulation or dynamic reconstruction models as proposed by 
Chow and Street (2009) give better results for the prediction of the TKE, but are often, due to the excessive computing resources needed, not applicable for simulations of longer time frames.

A completely new approach to make the simulation data with their short time frame of 10 min comparable to the $1.5 \mathrm{~h}$ of flight time was chosen in this study. The results look promising for the task of validating models using unmanned aircraft systems. Some limitations are still not overcome and add uncertainties to the analysis. One limitation of the chosen method is the difference in measurement heights of the UAS and the discrete heights of the model output. To obtain the same heights in the model and measurements, the original model output was interpolated to extract the flown altitudes of the UAS. Another interpolation was done to produce the contour plots. To overcome this issue it would be beneficial to tune the model outputs to give their discrete heights where the UAS was flying or will fly. Together with a higher temporal resolution, it would be possible to compare the measured heights directly with the simulations with identical timestamps. Even problems introduced by mesoscale fluctuations (e.g., a cold front) during the flight would be eliminated, making a comparison with measurements and the validation of models in complex terrain using UAS much easier.

\section{Conclusion}

The UAS MASC-3 was used to conduct measurements on two consecutive days in September 2018 over the WINSENT test site. Data from these flights were compared to numerical simulations of two stages of fidelity and the measured wind field was analyzed regarding its impact on the future wind turbines. This work extends the experiment from Wildmann et al. (2017) with a more precise measurement system and the possibility of measuring flow features very close to the ground over the escarpment and the plateau.

The conditions on both days were similar in respect to the wind direction and thermal stratification, with a slight instability on both days (Fig. 4). However, the wind speed for the first day was twice as high with slightly more fluctuations in wind speed and wind direction compared to the second day.

It was shown that the research UAS MASC-3 is capable of measuring a large area alongside the test field in complex terrain and still resolves small changes in all three wind components. Specifically the area above the escarpment and the plateau was of great importance. It was possible to measure down to $20 \mathrm{~m}$ above the plateau to get insight into the effect of trees and the additional turbulence they introduce.

Both models produced results in good agreement with the wind-field data measured by the UAS. Despite the coarse spatial resolution of the WRF model, it performed well in terms of predicting the areas of higher wind speeds and the inclination angle above the escarpment and the plateau. The OpenFOAM model gave better results than WRF for the wind speed compared to the measurements, good results for the inclination angle, and needs adjustments for the wind direction. The areas of higher TKE values in the lee of the trees were not captured properly by both models. Areas of high turbulence were located in higher altitudes and in regions before the edge of the slope. Having this in mind, a tuning of the WRF and OpenFOAM model to simulate the turbulence in the lowest $50 \mathrm{~m}$ above ground in the lee of the trees would be beneficial for understanding the effect of a forested escarpment onto the local wind field. 
The main results are:

- In Wildmann et al. (2017) it was not possible to see the impact of the forest on the flow in the lee of the trees. The measurements conducted in this study showed the capability of the MASC-3 to measure small-scale differences and phenomena of the wind field influenced by a forested escarpment. Features like the intense turbulence at low altitudes over the plateau and an over-speeding above the escarpment introduced by the orography and the forest were found. A recirculation is expected when the flow field is influenced as it is at that site. Despite past studies showing such an effect, a recirculation was not found. We assume the accelerated flow to mix further downstream on the plateau, where data are not available. The negative inclination angles in the east are an indicator for the flow recirculating, but no direct evidence was found.

- The measurements on both days showed an acceleration as well as a change in wind direction of the flow above the escarpment and the plateau close to the ground. Wind shear of more than $4 \mathrm{~m} \mathrm{~s}^{-1}$ with just 100-m difference in altitude above the plateau was found.

- The highest TKE was found to be in the lowest $80 \mathrm{~m}$ above ground behind the escarpment with the highest values in the lowest $50 \mathrm{~m}$.

- The wind field measured by the UAS is in good accordance with the results from both the WRF and the OpenFOAM model. The model's turbulence estimation need adjustments to provide better results for the wind field close to the ground in the lee of the trees.

Given the difficulties of comparing the gathered data from the UAS with the model data, the results of the new approach explained in Sect. 3.4 look promising and provide a good basis for future CFD simulations and their validation. However, the comparison is as of now limited to a single cross-section over a period of about $1.5 \mathrm{~h}$.

\section{Outlook}

To obtain an even better picture of the flow and local phenomena introduced into the flow by the complex terrain, more measurements need to be done. For future campaigns, a slightly extended approach would be beneficial. Specifically, measurements in the undisturbed flow upstream would help understanding of the overall situation. This approach will be realized by a multirotor UAS doing vertical profiles during the next larger flight campaign at the test site during each measurement flight with the MASC-3. Such vertical profiles in the undisturbed flow have a large value for CFD simulations. Furthermore, we aim at performing flights with a second MASC-3 in the valley and the lowland upstream of the escarpment in parallel to the measurements at the test site. Finally, given that the trees at the test site are mostly deciduous, we plan to repeat the experiment during winter to study the impact of leaves on the flow. Also, investigating the flow recirculation further down the plateau is a task for a future measurement campaign.

Acknowledgements We acknowledge support by Projekträger Jülich and the BMWi (Federal Ministry for Economic Affairs and Energy) that funded the WINSENT project (0324129D). We thank the ZSW (Zentrum für Sonnenenergie- und Wasserstoff-Forschung Baden-Württemberg) for supplying the meteorological tower data. For extensive technical support and piloting of the aircraft at the field campaign we want to thank Alexander Rautenberg. The authors also acknowledge the State of Baden-Württemberg through bwHPC (Baden-Württemberg High-Performance-Computing) for providing computational resources.

Funding Open Access funding enabled and organized by Projekt DEAL. 
Open Access This article is licensed under a Creative Commons Attribution 4.0 International License, which permits use, sharing, adaptation, distribution and reproduction in any medium or format, as long as you give appropriate credit to the original author(s) and the source, provide a link to the Creative Commons licence, and indicate if changes were made. The images or other third party material in this article are included in the article's Creative Commons licence, unless indicated otherwise in a credit line to the material. If material is not included in the article's Creative Commons licence and your intended use is not permitted by statutory regulation or exceeds the permitted use, you will need to obtain permission directly from the copyright holder. To view a copy of this licence, visit http://creativecommons.org/licenses/by/4.0/.

\section{References}

Ayotte G, Davy R, Coppin P (2001) A simple temporal and spatial analysis of flow in complex terrain. Boundary-Layer Meteorol 98:275-295. https://doi.org/10.1023/A:1026583021740

Belcher S, Harman I, Finnigan J (2012) The wind in the willows: Flows in forest canopies in complex terrain. Ann Rev Fluid Mech 44(1):479-504. https://doi.org/10.1146/annurev-fluid-120710-101036

Berg J, Mann J, Bechmann A, Courtney MS, Jørgensen HE (2011) The Bolund experiment, part i: flow over asteep, three-dimensional hill. Boundary-Layer Meteorol 141:219-243. https://doi.org/10.1007/s10546011-9636-y

Chow FK, Street RL (2009) Evaluation of turbulence closure models for large-eddy simulation over complex terrain: Flow over Askervein Hill. J Appl Meteorol Clim 48(5):1050-1065. https://doi.org/10.1175/ 2008JAMC1862.1

Clifton A, Daniels M, Lehning M (2014) Effect of winds in a mountain pass on turbine performance. Wind Energy 17(10):1543-1562. https://doi.org/10.1002/we.1650

El-Bahlouli A, Rautenberg A, Schoen M, zum Berge K, Bange J, Knaus H (2019) Comparison of CFD simulation to UAS measurements for wind flows in complex terrain: Application to the WINSENT test site. Energies. https://doi.org/10.3390/en12101992

El-Bahlouli A, Leukauf D, Platis A, zum Berge K, Bange J, Knaus H (2020) Validating CFD predictions of flow over an escarpment using ground-based and airborne measurement devices. Energies. https://doi. org/10.3390/en 13184688

Emeis S, Frank H, Fiedler F (1995) Modification of air flow over an escarpment - results from the Hjardemal experiment. Boundary-Layer Meteorol 74:131-161. https://doi.org/10.1007/BF00715714

Hofsaess M, Clifton A, Cheng P (2018) Reducing the uncertainty of lidar measurments in complex terrain using a linear model approach. Remote Sens. https://doi.org/10.18419/opus-10119

Knaus H, Hofsaess M, Rautenberg A, Bange J (2018) Application of different turbulence models simulating wind flow in complex terrain: A case study for the WindForS test site. Computation. https://doi.org/10. 3390/computation6030043

Kroll N, Eisfeld B, Bleecke H (1999) FLOWer. Notes Numer Fluid Mech 71:58-68

Lange J, Mann J, Angelou N, Berg J, Sjöholm M, Mikkelsen T (2016) Variations of the wake height over the Bolund Escarpment measured by a scanning lidar. Boundary-Layer Meteorol 159:147-159. https://doi. org/10.1007/s10546-015-0107-8

Letson F, Barthelmie R, Hu W, Pryor S (2018) Characterizing wind gusts in complex terrain. Atmos Chem Phys 19:3797-3819. https://doi.org/10.5194/acp-19-3797-2019

Letzgus P, Lutz T, Kraemer E (2018) Detached eddy simulations of the local atmospheric flow field within a forested wind energy test site located in complex terrain. J Phys Conf Ser. https://doi.org/10.1088/1742$6596 / 1037 / 7 / 072043$

Lu GY, Wong DW (2008) An adaptive inverse-distance weighting spatial interpolation technique. Comput Geo 34:1044-1055. https://doi.org/10.1016/j.cageo.2007.07.010

Mauz M, Rautenberg A, Platis A, Cormier M, Bange J (2019) First identification and quantification of detachedtip vortices behind a wind energy converter using fixed-wing unmanned aircraft system. Wind Energy Sci 4:451-463. https://doi.org/10.5194/wes-4-451-2019

Menke R, Vasiljević N, Mann J, Lundquist J (2019) Characterization of flow recirculation zones at the Perdigão site using multi-lidar measurements. Atmos Chem Phys 19(4):2713-2723. https://doi.org/10.5194/acp19-2713-2019

Rautenberg A, Graf M, Wildmann N, Platis A, Bange J (2018) Reviewing wind measurement approaches for fixed-wing unmanned aircraft. Atmosphere. https://doi.org/10.3390/atmos9110422

Rautenberg A, Schoen M, zum Berge K, Mauz M, Manz M, Platis A, van Kesteren B, Suomi I, Kral S, Bange J (2019) The Multi-purpose Airborne Sensor Carrier MASC-3 for wind and turbulence measurements in the atmospheric boundary layer. Sensors. https://doi.org/10.3390/s19102292 
Schmugge TJ, Abrams MJ, a B Kahle, Yamaguchi Y, Fujisada H, (2003) Advanced spaceborne thermal emission and reflection radiometer (ASTER). Remote Sensing for Agriculture, Ecosystems, and Hydrology IV 4879: https://doi.org/10.1117/12.469693

Shaw RH, Schumann U (1992) Large-eddy simulation of turbulent flow above and within a forest. BoundaryLayer Meteorol 61:47-64. https://doi.org/10.1007/BF02033994

Skamarock WC, Klemp J, Dudhia J, Gill D, Barker D, Duda M, Huang X, Weng W, Powers J (2008) A description of the advanced research WRF version 3. National Center for Atmospheric Research, Tech rep

Talbot C, Bou-Zeid E, Smith J (2012) Nested mesoscale large-eddy simulations with WRF: Performance in real test cases. J Hydrometeorol 13:1421-1441. https://doi.org/10.1175/JHM-D-11-048.1

Van den Kroonenberg A, Martin T, Buschmann M, Bange J, Voersmann P (2008) Measuring the wind vector using the autonomous mini aerial vehicle $\mathrm{M}^{2} \mathrm{AV}$. J Atmos Ocean Technol 25:1969-1982. https://doi.org/ 10.1175/2008JTECHA1114.1

VDE (2019) DIN EN IEC 61400-1 VDE 0127-1:2019-12; Standards-VDE. VDE Verlag GmbH, Tech rep

Wagenbrenner N, Forthofer J, Lamb B, Shannon K, Butler B (2016) Downscaling surface wind predictions from numerical weather prediction models in complex terrain with windNinja. Atmos Chem Phys 16:52295241. https://doi.org/10.5194/acp-16-5229-2016

Weller HG, Tabor G, Jasak H, Fureby C (1998) A tensorial approach to computational continuum mechanics using object-oriented techniques. Comput Phys 12(6):620-631. https://doi.org/10.1063/1.168744

Wildmann N, Hofsaess M, Weimer F, Joos A, Bange J (2014) MASC - a small remotely piloted aircraft (RPA) for wind energy research. Adv Sci Res 11:55-61. https://doi.org/10.5194/asr-11-55-2014

Wildmann N, Bernard S, Bange J (2017) Measuring the local wind field at an escarpment using small remotelypiloted aircraft. Renew Energy 103:613-619. https://doi.org/10.1016/j.renene.2016.10.073

WindEurope (2019) WindEurope Annual Statistics 2019. https://windeurope.org/wp-content/uploads/files/ about-wind/statistics/WindEurope-Annual-Statistics-2019.pdf

Publisher's Note Springer Nature remains neutral with regard to jurisdictional claims in published maps and institutional affiliations. 